\title{
An ancient role for the Hippo pathway in axis formation and morphogenesis
}

Maria Brooun ${ }^{*}$, Willi Salvenmoser ${ }^{2}$, Catherine Dana ${ }^{3}$, Marius Sudol $^{4}$, Robert Steele ${ }^{3}$, Bert Hobmayer ${ }^{2}$, Helen McNeill ${ }^{*}$

${ }^{1}$ Lunenfeld-Tanenbaum Research Institute, Toronto, ON, M5G 1X5, Canada

2 Department of Zoology and Center for Molecular Biosciences Innsbruck, University of Innsbruck, Technikerstr. 25, A-6020 Innsbruck, Austria

${ }^{3}$ Department of Biological Chemistry, School of Medicine, University of California, Irvine, CA 92697-1700

${ }^{4}$ Icahn School of Medicine at Mount Sinai, Department of Medicine, One Gustave Levy Place, New York, NY 10029, USA

${ }^{5}$ Department of Developmental Biology , Washington University School of Medicine, 4577 McKinley Avenue, St. Louis, Missouri 63110-1093

*authors for correspondence: Maria Brooun (brooun@lunenfeld.ca), Helen McNeill (mcneillh@wustl.edu) 


\section{Summary}

How did cells of early metazoan organisms first organize themselves to form a body axis? The canonical Wnt pathway has been shown to be sufficient for induction of axis in Cnidaria, a sister group to Bilateria, and is important in bilaterian axis formation. Here, we provide experimental evidence that in cnidarian Hydra the Hippo pathway regulates the formation of a new axis during budding upstream of the Wnt pathway. The target of Hippo pathway, the transcriptional co-activator YAP, inhibits the initiation of budding in Hydra, and is regulated by Hydra LATS. In addition, we show functions of Hippo pathway in regulation of actin organization and cell proliferation in Hydra. We hypothesize that Hippo pathway served as a link between continuous cell division, cell density and axis formation early in metazoan evolution.

\section{Introduction}

How animals establish and pattern their primary body axis is a fundamental problem in biology. Data from a wide range of bilaterian animals suggest that Wnt signaling controls posterior identity during body plan formation [1-3]. Wht also drives axis formation in Cnidaria, the sister phylum to Bilateria. [4-7]. Thus, an axial patterning role for Wnt signaling was present in the last common ancestor of Cnidaria and Bilateria, which diverged $\sim 650$ million years ago.

Hydra, a small freshwater cnidarian with a simple body plan, exhibits amazing regenerative and budding capabilities, as described in 1744 by Trembley [8]. The Hydra body is essentially a tube of epithelial cells, aligned along the oral-aboral axis (Figures 1A and B). Hydra has only two epithelial layers, an ectoderm and endoderm, separated by an extracellular matrix called the mesoglea (Figure 1C). Epithelial cells of both layers are attached to the mesoglea and exhibit actin-myosin contractile elements called muscle processes on their basal sides (Figures $1 \mathrm{C}$ and D). Cells of the interstitial cell lineage, stem cells which give rise to nerves, nematocytes, gland cells, and germ cells cells [9], are intermingled among the epithelial cells (Figure 1C). Epithelial cells continuously divide and are displaced along the oral-aboral axis towards the head and foot. The balance between cell production and loss of cells via sloughing from the ends and bud formation determines the size of the animal $[10,11]$ (Figure 1B). 
Tentacles and buds form by tissue evagination. Budding, Hydra's asexual form of reproduction, generates a new new body axis [12] (Figures 1B and E). Bud induction depends on the size of the mother polyp and its epithelial growth rate [13]. Budding becomes visible by a thickening of the ectoderm at a site in the lower half of the body column (stage 1 in Figure 1E; Figure 1F) and continues as evagination of both layers. The formation of a new axis in Hydra is also controlled by the Wnt/ $\beta$-catenin pathway $[4,6]$. Experimental activation of Wnt signaling in the body column results in formation of ectopic axes [4, 6, 14-16]. Expression of $H y W n t 3$ is detected early in budding, but only after thickening of the ectoderm is visible $[14,17]$. It is unknown what pathway(s) leads to the thickening of the ectoderm and induction of HyWnt3.

The Hippo pathway is a key regulator of cell proliferation, differentiation, and apoptosis [18]. It consists of a cascade of kinases that controls nuclear localization of the transcription factor Yap (Yorkie in Drosophila) (Figure 1G). MST (Drosophila Hippo) kinase phosphorylates and activates LATS (Drosophila Warts) that, in turn, phosphorylates Yap (Yorkie) leading to its binding to 14-3-3 and cytoplasmic retention or ubiquitination and degradation [21]. Nuclear Yap/Yorkie, which promotes the expression of pro-proliferative and anti-apoptotic genes, is involved in regulation of organ size [21, 22] and morphogenesis [23].

The Hippo pathway is remarkably conserved in metazoans and their unicellular ancestors [24]. Functional studies using Hippo, Warts, and Yorkie homologues from the unicellular holozoan Capsaspora owczarzaki proteins ectopically expressed in Drosophila indicate the growth-regulating capabilities of the Hippo pathway were established before the emergence of metazoans [24]. The full repertoire of proteins making up the Hippo cascade has been identified in Ctenophora and Cnidaria [25, 26]. Immunostaining analysis of Yap in the cnidarian Clytia hemisphaerica suggested that regulation of nuclear/cytoplasmic localization of Yap could be a mechanism halting cell division and triggering differentiation programs [25]. However, the function of the Hippo pathway has not been elucidated in cnidarians.

Here, we investigate the role of the Hippo pathway in morphogenesis and axis formation in Hydra. Using shRNA-mediated knockdown as well as a gain of function transgenic approach, we show that the Hippo pathway components LATS and YAP regulate axis formation and morphogenesis in Hydra. Our studies indicate that the Hippo pathway affects epithelial growth and acts upstream of Wnt3a during axis formation in Hydra, suggesting that linkage between these two signalling pathways was a key step in the evolution of axis formation in metazoans. 
A

\section{C}
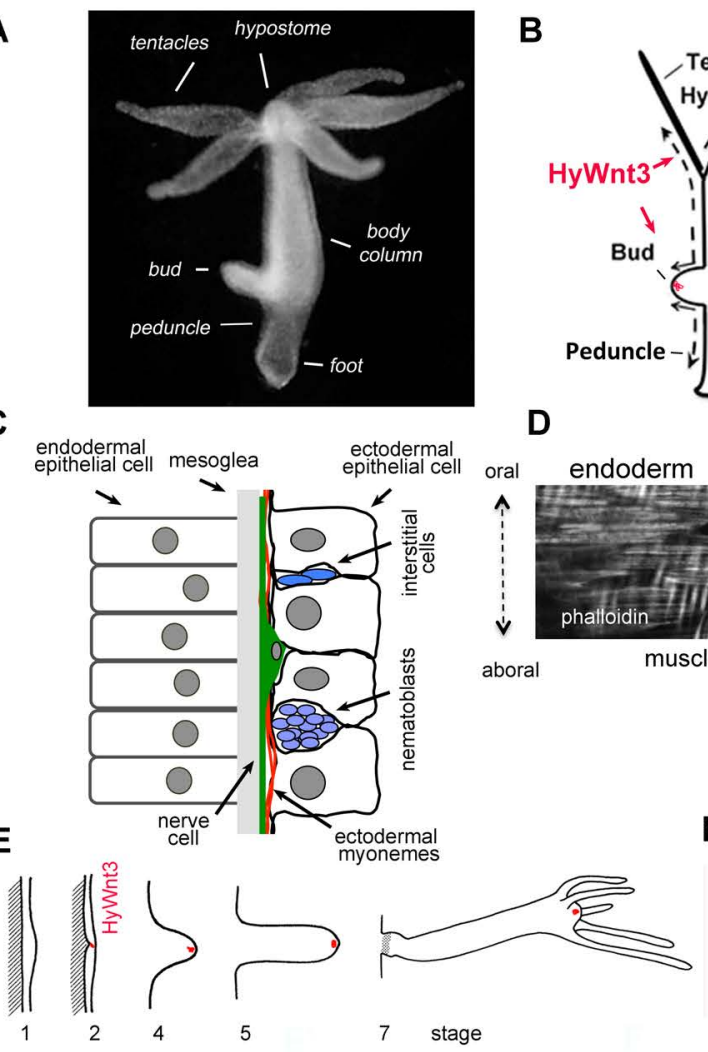

F

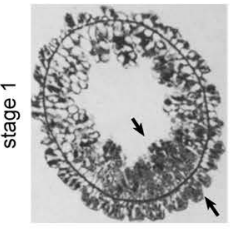

G

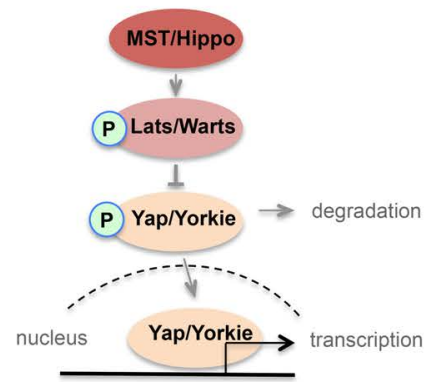

H

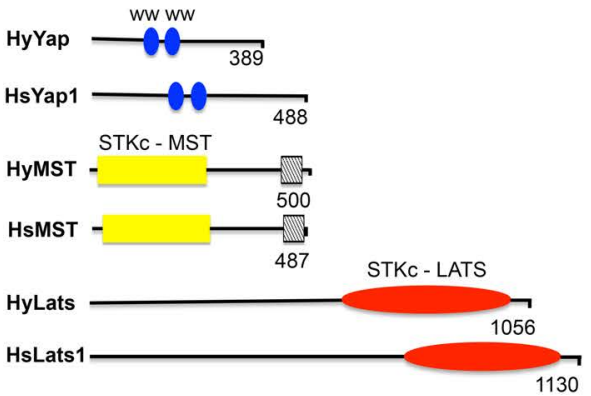

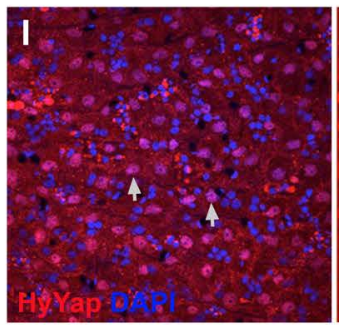
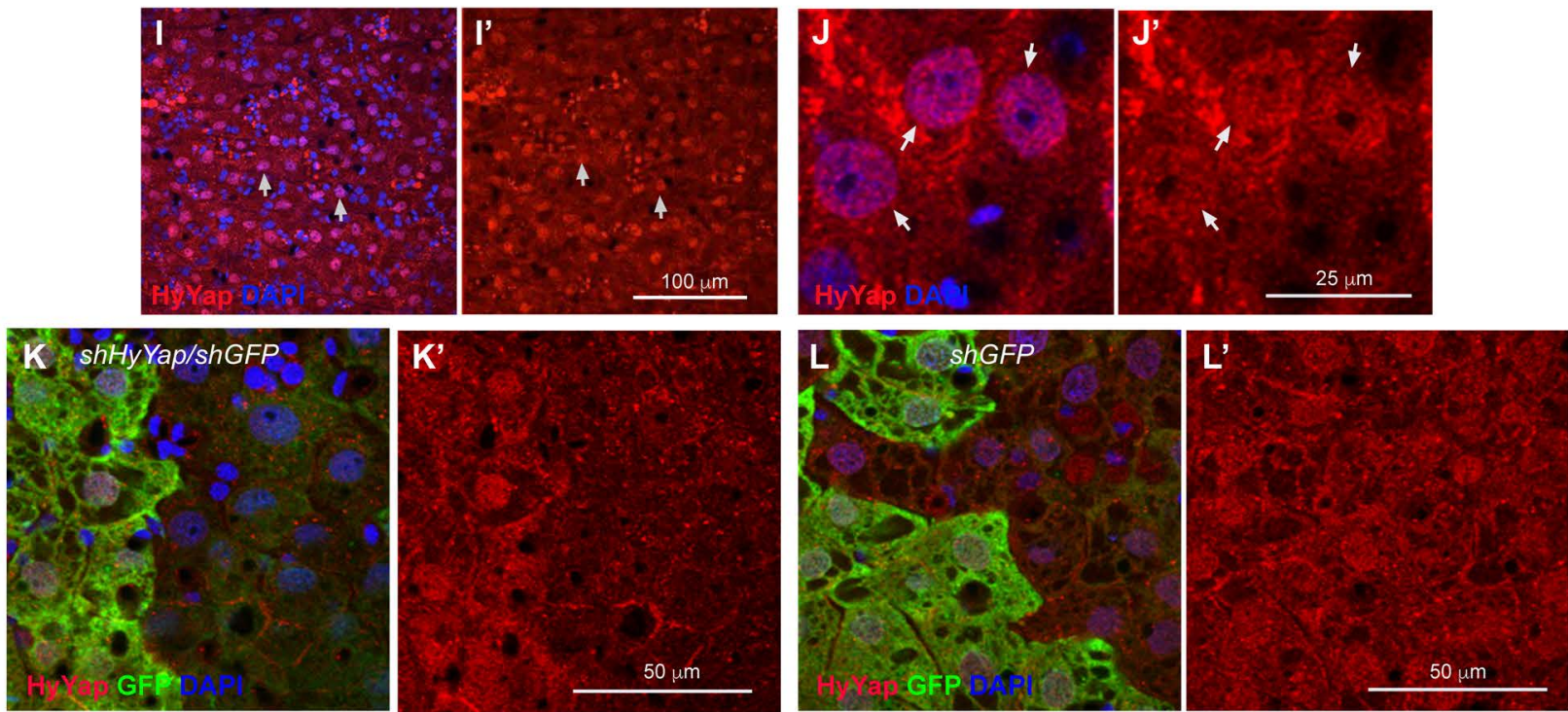

Figure 1 Hydra homologue of YAP is expressed in ectodermal epithelial cells.

(A) Photo of a live Hydra.

(B) Schematic of Hydra body plan; arrows indicate directions of cell displacement along the oral/aboral axis.

(C) Schematic of a section through Hydra body column. 
(D) Hydra endodermal and ectodermal muscle processes visualized with phalloidin.

(E) Schematic of Hydra budding (adapted from [19]). The area of expression of HyWnt3 is confined to about 50 ectodermal epithelial cells marked in red [14].

(F) Stage 1: transverse section through the budding zone, arrows indicate increased cell density in the ectoderm and endoderm (adapted from [20]).

(G) Schematic of Hippo pathway.

(H) Schematic of Hydra and mammalian homologues of Yap, MST and LATS proteins; WW proline-rich sequences binding domain, STKc-MST1/2 catalytic domain of MST family of serine/threonine kinases, - MST1-SARAH - apoptosis-mediating domain, STKc-LATS catalytic domain of LATS family of serine/threonine kinases.

(I - J') Apical view of Hydra ectoderm immunostained with anti-HyYap serum. Arrows point to the nuclei of ectodermal epithelial cells.

(K - L') Apical view of ectoderm of GFP polyp electroporated with shGFP/HyYap (K, K'), shGFP alone(L, L') hairpins and immunostained with anti-GFP and anti-HyYap antibodies.

\section{Results}

\section{HyYap regulates proliferation in Hydra}

Transcriptomic and genomic data identified single homologues of Yap, Lats and MST in Hydra vulgaris, which we refer to as HyYap, HyLATS and HyMST (Figure 1H and Figues S1A, B and C), consistent with recent studies [27]. To explore HyYap function in vivo, we generated antiserum against residues 1 - 159 of the protein. Immunostaining of Hydra polyps revealed HyYap in the nuclei and cytoplasm of ectodermal epithelial cells (Figures 1I - J'). Both nuclear and cytoplasmic staining were specifically removed by pre-absorption of anti-HyYap serum with HyYap-GST antigen (Figure S1E). The distribution of HyYap was similar to the subcellular distribution of mammalian and Drosophila Yap homologues [28, 29]. Immunoblotting of Hydra lysates with the anti-HyYap serum revealed a single strong band which was lost by pre-absorption with HyYap-GST antigen (Figure S1D) and by shRNA knockdown (see below).

To explore the function of HyYap, we combined shRNA knockdown protocols developed for Hydra [30,31] and for the sea anemone Nematostella vectensis [32]. To optimize the protocol, we used a transgenic Hydra line expressing GFP in the ectodermal epithelial cells [33]. Transgenic polyps were electroporated with shGFP, 
leading to mosaic downregulation of GFP. Downregulation of GFP was seen on one side of $60-70 \%$ of the electroporated polyps $4-5$ days after electroporation, and was visible 4 weeks after electroporation (Figure S2A). These data indicated that electroporation is an effective way to generate mosaic loss of function in Hydra. Mosaic loss of function has been a powerful tool in Drosophila, and we show here that this is also the case in Hydra.

To knock down HyYap, GFP-expressing polyps were electroporated with a mixture of shGFP hairpins and two different shHyYap hairpins, shHyYap1 and sHyhYap2 (Table S1, shHyYap further in text). Electroporation with a combination of shGFP and shHyYap dramatically reduced both nuclear and cytoplasmic HyYap staining (Figures $1 \mathrm{~K}$ and $\mathrm{K}^{\prime}$ ). Importantly, HyYap staining was not affected by electroporation with a combination of shGFP and shHyYapscr or shGFP alone (Figures 1L, L' and S2B). Knocking down of HyYap was confirmed by qPCR and immunoblot analyses (Figures S2C - E). Importantly, all GFP-negative cells were also HyYap-negative, i.e. all affected cells received both shGFP and shHyYap hairpins, leading to a reduction in the level of both proteins in the cell (Figures $1 \mathrm{~K}$ and $\left.\mathrm{K}^{\prime}\right)$.

Mammalian and Drosophila Yap homologues promote proliferation [21, 34]. To determine if Yap regulates proliferation in Hydra, we performed EdU incorporation assays on GFP-expressing polyps electroporated with shGFP alone, with shGFP and shHyYap, or with shGFP and shHyYapscr. The graph in Figure S2H shows the ratio of EdU-positive $\mathrm{GFP}^{+}$cells to EdU-positive GFP- cells determined for each individual polyp $5-6$ days after electroporation. These results demonstrate that reduction of HyYap significantly slows the cell cycle, consistent with a role for HyYap in promoting cell proliferation.

\section{HyYap represses bud formation}

Unexpectedly, knockdown of HyYap caused a significant increase in the number of polyps with buds (Figure 2A). All buds formed at the normal location, the budding zone. Budding normally starts with an evagination of both ectoderm and endoderm, with the epithelial cells where budding is initiated forming the tip of the bud [19]. Staining for GFP and HyYap revealed that the majority of bud tips formed from cells lacking HyYap, indicating that budding was initiated in cells that had lost HyYap (Figures 2B - C'). 
Since downregulation of HyYap led to bud formation, we hypothesized that budding normally occurs in areas of low HyYap expression. We quantified HyYap staining in ectodermal epithelial cells along the body column of the polyp (Figures 2D - G'). Staining intensities were measured in the nucleus and cytoplasm for each cell. Interestingly, both the lowest level of nuclear HyYap (Figure $2 \mathrm{H}$ ) and the lowest nuclear/cytoplasmic ratio of HyYap were observed in the budding zone (Figure 2I). In contrast, the highest level of nuclear HyYap, and highest nuclear/cytoplasmic HyYap ratio were observed in tentacles and the peduncle (Figures $2 \mathrm{H}$ and $\mathrm{I}$ ).
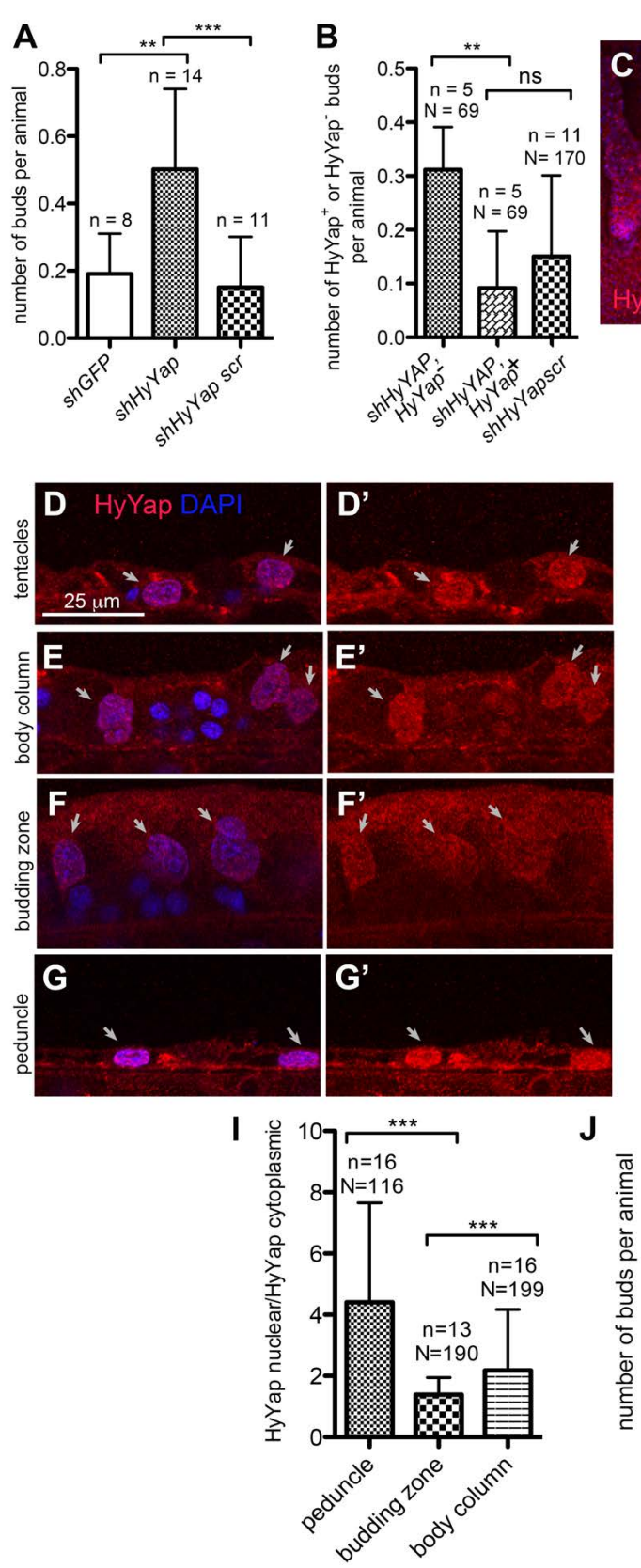

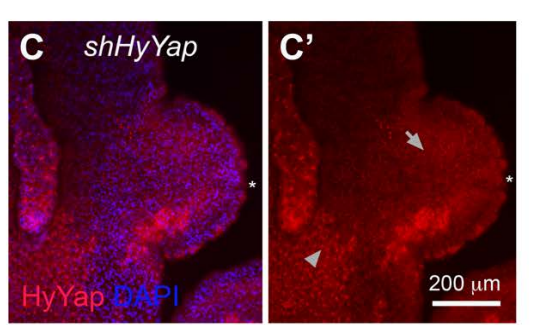

Single cell transcriptome data indicate that HyYap is expressed in the interstitial cell lineage [27, 35]. To determine if ectopic budding is caused by loss of HyYap in ectodermal epithelial cells or interstitial cells, polyps were treated with $10 \mathrm{mM}$

\section{Figure 2 HyYap is a negative regulator of Hydra budding.}

(A) Graph showing an increased rate of budding in polyps electroported with shHyYap compared to controls; $\mathrm{n}$ - number of experiments, each experiment included 10 20 polyps.

(B) Graph shows that a significant majority of buds developed in polyps electroporated with shHyYap originated from HyYap tissue; $\mathrm{n}$ - number of experiments, $\mathrm{N}$ - total number of polyps used in analysis.

(C, $\mathrm{C}^{\prime}$ ) Lateral view of a bud developing from HyYaptissue; asterisk points to the tip of the bud, arrow - to 
HyYap- tissue, arrowhead - to HyYap ${ }^{+}$tissue.

(D - G') Lateral view of the ectoderm of tentacles (D, D'), body column (E, E'), budding zone (F, F') and a peduncle $\left(G, G^{\prime}\right)$ immunostained with anti-HyYap serum; arrows point to nuclei of ectodermal epithelial cells.

(H) Graph shows the intensities of HyYap immunostaining in nuclei of tentacles, body column, budding zone and a peduncle normalized for intensity in the nuclei of a body column and superimposed on a schematic drawing of Hydra; for each animal, the average intensity of immunostaining was measured in the nuclei of ectodermal epithelial (10 - 20 nuclei for each area); $\mathrm{n}$ - number of polyps.

(I) Graph shows nuclear/cytoplasmic ratio of HyYap in the body column, budding zone, and peduncle determined by immunostaining for each cell; $\mathrm{N}$ - number of cells, $\mathrm{n}$ - number of polyps. (J) Graph shows the budding rate in animals treated with $10 \mathrm{mM}$ hydroxyurea for $48 \mathrm{~h}$ prior to electroporation; $\mathrm{n}$ - number of experiments, $\mathrm{N}$ - number of polyps.

hydroxyurea (HU) for $48 \mathrm{~h}$ prior to electroporation. This treatment eliminates at least $50 \%$ of interstitial cells from the body column, without affecting the number of epithelial cells [36]. Increased budding was still observed upon HyYap knockdown (Figure 2J), implying that HyYap functions in epithelial cells to restrict budding. Together these data indicate that HyYap acts as a negative regulator of budding and suggested that control of the nuclear/cytoplasmic distribution of HyYap may be an important mechanism for regulating bud initiation.

\section{HyLATS regulates HyYAP localization and bud formation}

LATS kinases phosphorylate YAP, promoting its retention in the cytoplasm and degradation (Figure 1G) [21, 22, 37]. Reduced LATS, thus, promotes active, nuclear YAP. We generated polyps mosaic for HyLATS knockdown by electroporating GFPexpressing polyps with shHyLATS/shGFP (Table S1). Electroporation resulted in a significant decrease of HyLATS mRNA (Figure S2I). Importantly, immunostaining revealed increased nuclear accumulation of HyYap in epithelial cells electroporated with shHyLATS and shGFP (Figures 3A, A', A1, A2 and B). The nuclear/cytoplasmic ratio of HyYap was also significantly higher in cells electroporated with shHyLATS (Figure 3C). Thus LATS regulates Yap nuclear localization in Hydra, as it does in bilaterians.

Since knocking down HyLATS resulted in increased nuclear accumulation of HyYap, we expected a concomitant increase in epithelial cell proliferation. Indeed, incorporation of EdU was higher in HyLATS knockdown cells than in GFP knockdown controls, but not significantly higher (Figure S2H). This may be explained by incomplete knockdown of HyLATS. Significantly, knocking down 
HyLATS halted production of buds (Figure 3D). Bud formation was rescued when animals were electroporated with a combination of shHyYap and shHyLATS (Figure 3D). These data imply that the amount of nuclear HyYap in ectodermal epithelial cells of the budding zone is a controlling factor for bud formation.

To test the effects of overexpression of nuclear HyYap, we generated a transgenic Hydra line that constitutively expressed a gain of function mutant HyYap in ectodermal epithelial cells (Figures S3A, B and C). HyYapS72A, bore a S72A
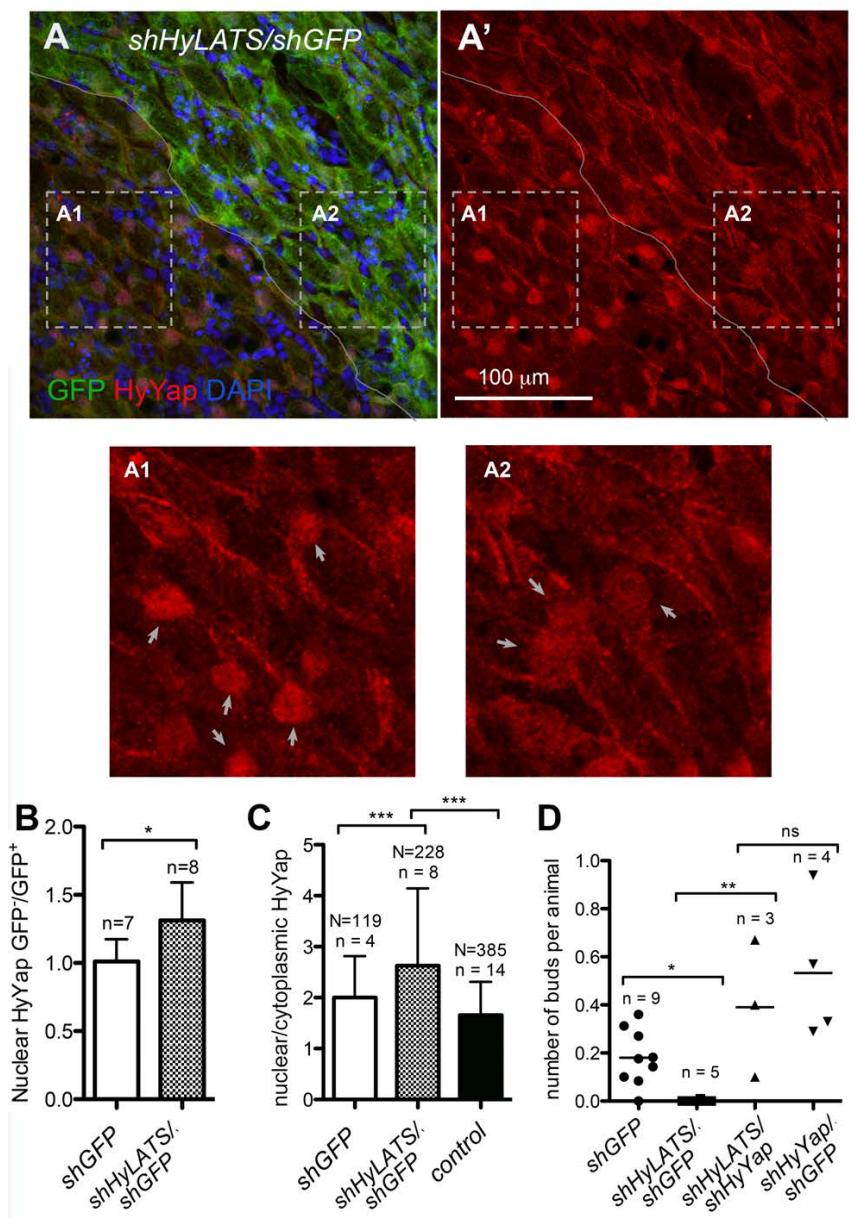

\section{Figure 3 HyLATS regulates cellular localization of HyYap and the budding rate.}

(A, A', A1, A2) Apical view of Hydra ectoderm electroporated with shHyLATS/shGFP and immunostained for GFP and HyYap; the border between $\mathrm{GFP}^{+}$and GFP- areas is marked; arrows point to nuclei; panels A1 and A2 are high magnification of GFP- and $\mathrm{GFP}^{+}$areas. Nuclear abundance of HyYap increases in GFPectodermal epithelial cells.

(B) Graph shows the ratio of nuclear HyYap intensities between GFP- and GFP ${ }^{+}$areas of GFP polyps electroporated with either shGFP or shGFP/shHyYap. Note, that electroporation with shGFP alone does affect the nuclear abundance of HyYap (GFP-/GFP+ 1). The average intensities of immunostaining were measured and the ratios were calculated individually for each animal; $\mathrm{n}=$ number of polyps.

(C) Graph shows the ratio between nuclear and cytoplasmic HyYap in non-electroporated GFP+ ectodermal epithelial cells (green bar), cells

electroporated with shGFP alone, and cells electroporated with shGFP/shHyLats.

Nuclear/cytoplasmic ratio was measured and calculated for each individual cell; $\mathrm{N}$ - number of cells, $\mathrm{n}$ - number of polyps.

(D) Graphs shows the budding rate of hydras electroporated with either shGFP (control), or shHyLats/shGFP, or shHyLats/shHyYap, or shHyYap/shGFP; $\mathrm{n}$ - number of experiments, in each experiment 10 - 20 polyps were used in each experiment for each condition. 
substitution that should make it resistant to LATS phosphorylation and subsequent cytoplasmic retention and degradation [29]. The use of an operon expression construct marked HyYapS72A-expressing cells with DsRed2. We were able to establish a culture of mosaic (30\% - 70\% transgenic cells) HyYapS72A animals. These animals had markedly reduced budding (Figure S3D), and eventually lost the ability to propagate. Thus, loss of HyYap increases budding and loss of HyLATS or constitutive HyYap gain of function suppresses budding. These data indicate that the Hippo pathway acts as a regulator of bud formation.

\section{Inhibition of the Hippo pathway alters Hydra morphology}

In addition to suppression of budding, knockdown of HyLATS had a strong effect on morphology. Tentacles containing cells in which HyLATS was knocked down became shorter and thicker (Figures $4 \mathrm{~A}$ and $\mathrm{B}$ ). We wondered if these dramatic alterations in morphology were due to overactivation of HyYap. Significantly, double electroporation of shHyLATs and shHyYap rescued the morphological defects caused by loss of HyLATS (Figure 4B) indicating that the thick tentacles were the result of excess HyYap activity.

The epithelial cells of the body column of Hydra are continually displaced into the tentacles, where they arrest in the G2 phase of the cell cycle and terminally differentiate (Figure 1B) [10]. EdU labeling indicated LATS knockdown cells still underwent G2 arrest. HyWi, the Hydra homologue of piwi $[11,38]$ marks undifferentiated epithelial cells (i.e. cells that have not been displaced into the tentacles or the basal disk). Immunostaining with HyWi antibodies showed no change compared to controls (Figures 4C - F'), indicating LATS knockdown did not prevent formation of differentiated cells.

Examination of the thick tentacles and the body column below them revealed thickening of the ectoderm (Figures 4G, $\mathrm{H}$ and I), an accumulation of ectopic actin fibers (Figures $4 \mathrm{H}-\mathrm{K}$ ), and accumulation of myosin along the apical surface of ectodermal epithelial cells (Figures 4L and M).

Consistent with the results of HyLATS knockdown, mosaic HyYapS72A transgenic polyps also often developed short thick tentacles (Figure S3B). HyYapS72A transgenic cells were elongated in the apico-basal direction and had ectopic actin fibers (Figures S3C, E, F and G) as in HyLATS knockdown polyps. These data support the proposal that HyLATS and HyYAP act together in a pathway to regulate 
A
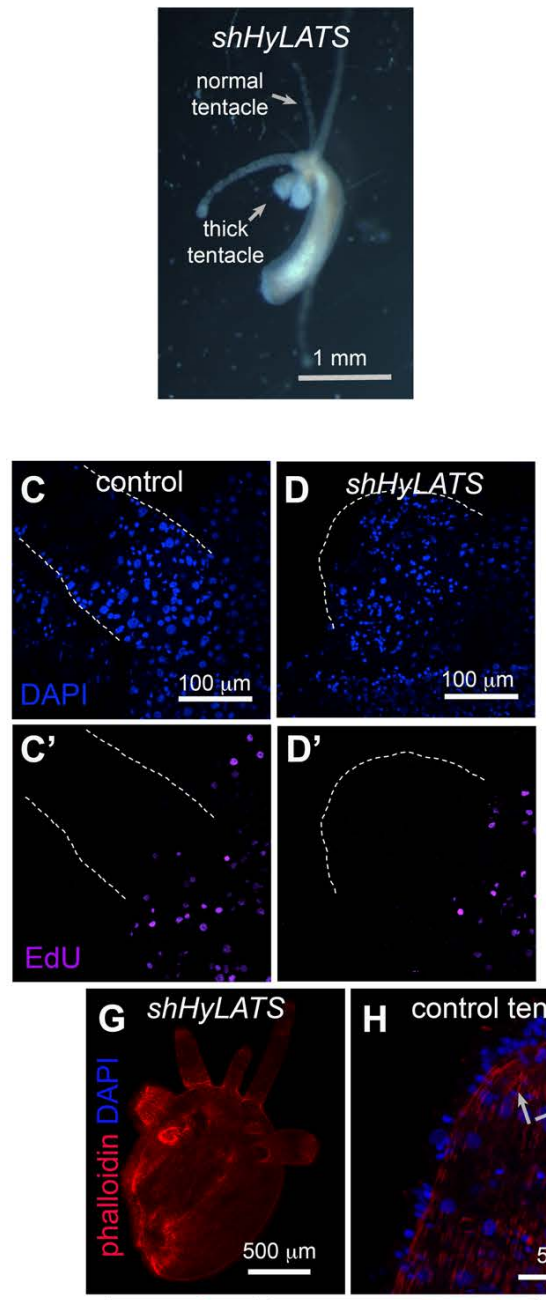

H control tentacle
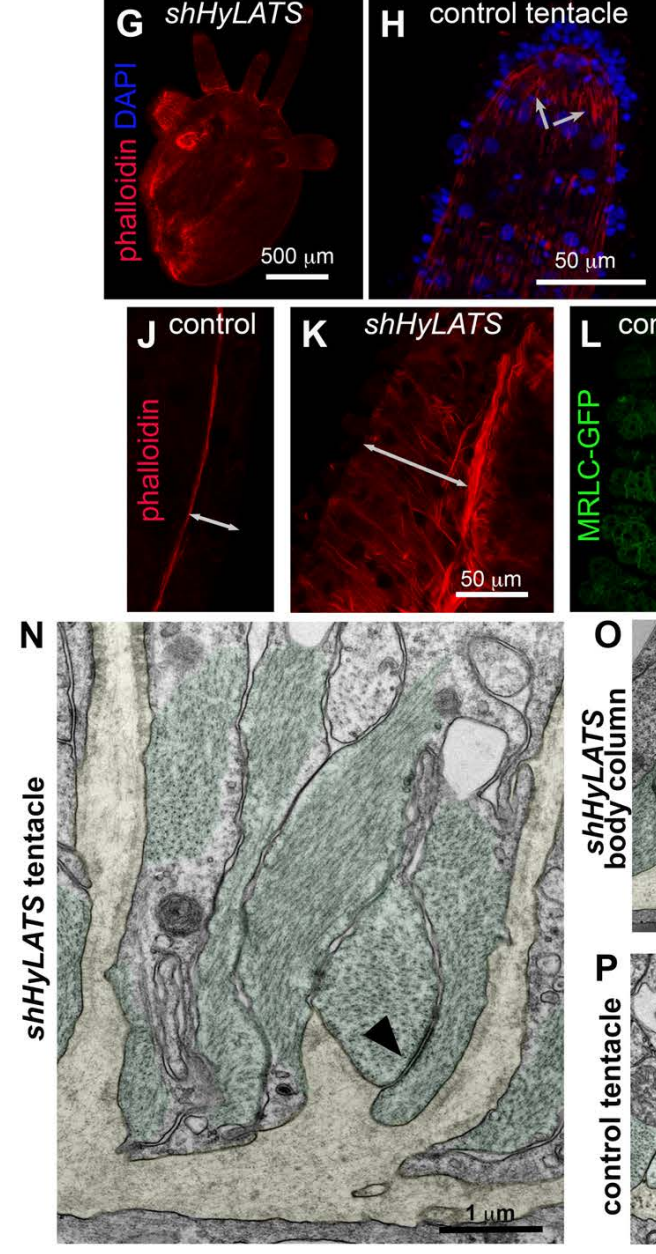

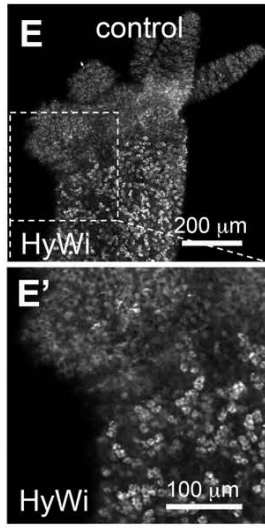

F ShHyLATS
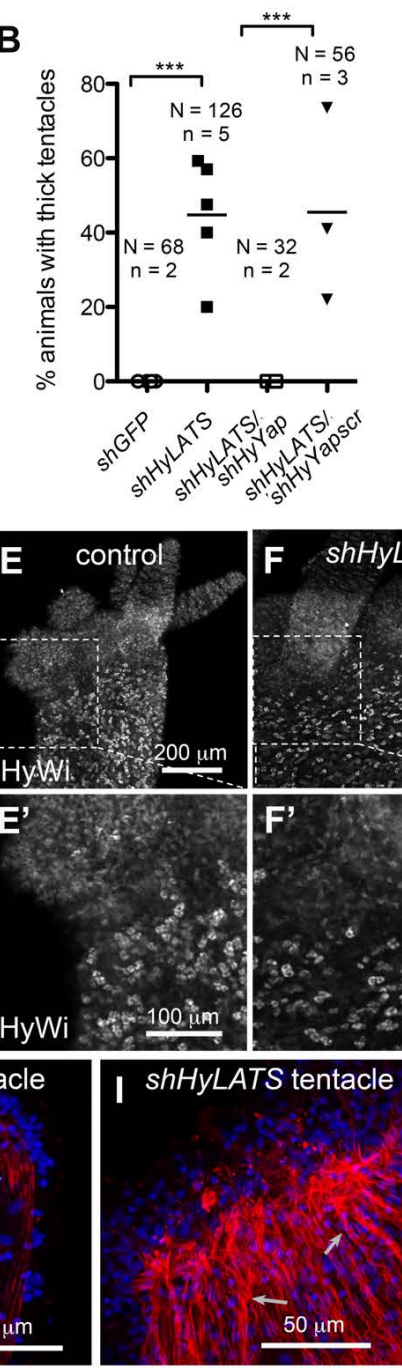

Lontrol
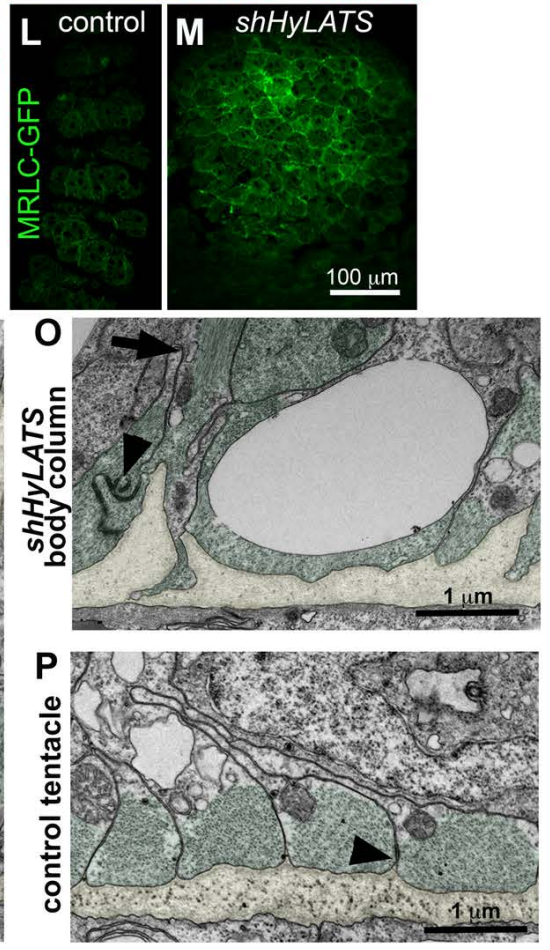

11
Figure 4 Inhibition of Hippo pathway changes Hydra morphology.

(A) Live polyp electroporated with shHyLats, 14 days after electroporation.

(B) Graph shows the percentage of thick tentacle formation in polyps electroporated with shGFP (control), shHyLATS alone, shHyLATS/shHyYap and shHyLATS/shHyYapscr; $\mathrm{N}$ number of polyps, $\mathrm{n}$ - number of experiments.

$\left(C-D^{\prime}\right)$ EdU is not detected in either control (C, C') or thick (D, D') tentacles. Edges of tentacles are outlined by dotted lines. $\left(E-F^{\prime}\right)$ The stem/progenitor marker HyWi is not detected in either control (E, E') or thick (F, $\left.F^{\prime}\right)$ tentacles.

(G) Hydra polyp electroporated with ShHyLATS and stained with phalloidin, 12 days after

electroporation. Visible tear along the body column is an artifact of fixation and is common when shortened shHyLats electroporated polyps are fixed. $(\mathrm{H}, \mathrm{I})$ Ends of normal $(\mathrm{H})$ and thick (I) tentacles stained with phalloidin. Arrows point to the ectodermal muscle processes that are filled with actin fibers and oriented along the length of the tentacle.

(J, K) Lateral view of the ectoderm of the body columns underneath normal tentacle (J) and thick (K) tentacle stained with phalloidin. Double-headed arrows indicated the thickness of the ectoderm 
$(\mathrm{L}, \mathrm{M})$ Apical view of the normal (L) and thick (M) tentacles of MRLC-GFP polyps immunostained for GFP.

(N - P) Transmission electron microscopy of cross sections visualizing the basal compartment of ectodermal epithelial cells in shHyLats tentacles (N), shHyLats body column (O), and wild type tentacles (P). (N, O) Muscle processes (green) exhibit abnormal elongation along the apical-basal axis of the cells and sometimes ectopic positioning distant from the mesoglea. Muscle processes remain connected by normal numbers of spot desmosome-like junctions (arrowheads), but they show a dramatic loss of their parallel alignment along the polyp's oral-aboral body axis as shown in wild type controls (P). (N, O) At positions, where the disrupted planar array of muscle fibers had gaps, the mesoglea (yellow) folded into the cytoplasm of the ectodermal epithelial cells without losing the hemidesmosome-like junctions usually located at the basal membrane surface of epithelial cells. (0) shows a representative image with an ectopic muscle process running along the apical-basal axis (arrow) pointing toward the mesoglea folding.

body morphology. Eventually, cells expressing HyYapS72A took over the animal and due to morphological defects the animals were unable to feed themselves and died.

To understand the cellular basis for the altered morphology, we analyzed ultra-thin sections of shHyLATS thick tentacles and adjacent body column tissue using transmission electron microscopy. While the apical compartment of ectodermal epithelial cells and the endodermal layer did not exhibit obvious defects in cytoplasmic organization, there was a dramatic loss of normal structure in the basal part of ectodermal epithelial cells (Figures $4 \mathrm{~N}$ - P, Figure S4). HyLATS knockdown affected shape, positioning, and orientation of muscle processes. We observed gaps in the planar array of the processes, individual processes elongated along the cells apical-basal axis, and some processes detached from the mesoglea. The parallel alignment of neighboring processes was strongly disrupted and randomized, sometimes even the parallel alignment of actin filaments within a muscle process was lost (Figures $4 \mathrm{~N}$ and 0 ). There was a clear loss of planar polarity in this tissue layer. Interestingly, the mesoglea adjacent to the shHyLATS knockdown cells showed folding towards the apical surface of the ectoderm (Figures $4 \mathrm{~N}$ and $\mathrm{O}$, Figures S4C and D). In the body column, we detected muscle processes apical to the tip of mesoglea folding running perpendicular to their normal planar orientation (Figure 40). Thus, disruption of the normal, non-folded mesoglea sheet may be a result of contraction of these ectopic muscle fibers along the epithelial cell's apical-basal axis. shHyLATS tentacle and body column tissue both showed these defects, but knockdown phenotypes were clearly stronger in the tentacles than in the body column. 


\section{The Hippo pathway acts upstream of the canonical Wnt pathway during budding}

The canonical Wnt pathway is activated early in budding, and induces axis formation in Hydra [4, 6, 14]. Experimental activation of the Wnt pathway in the Hydra body column leads to induction of ectopic axes, and inhibition of Wnt signaling blocks axis formation [4, 16]. Since knocking down of HyYap led to increased bud formation, we hypothesized that the Hippo pathway lies upstream of Wnt/ $\beta$-catenin signaling. In early buds, HyWnt3 expression is seen in a patch of $15-$ 20 cells, soon after thickening of the ectoderm and expression, and remains at the tip of the growing bud [14] (Figures 1E and 5A). To test the effects of the Hippo pathway on canonical Wnt signaling, we first examined expression of $H y W n t 3$ upon loss of HyYap. Significantly, more polyps electroporated with shHyYap had HyWnt3 patches in the budding zone than controls (Figure 5B).

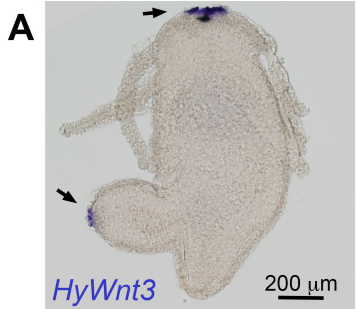

B

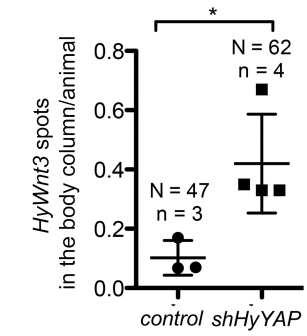

E
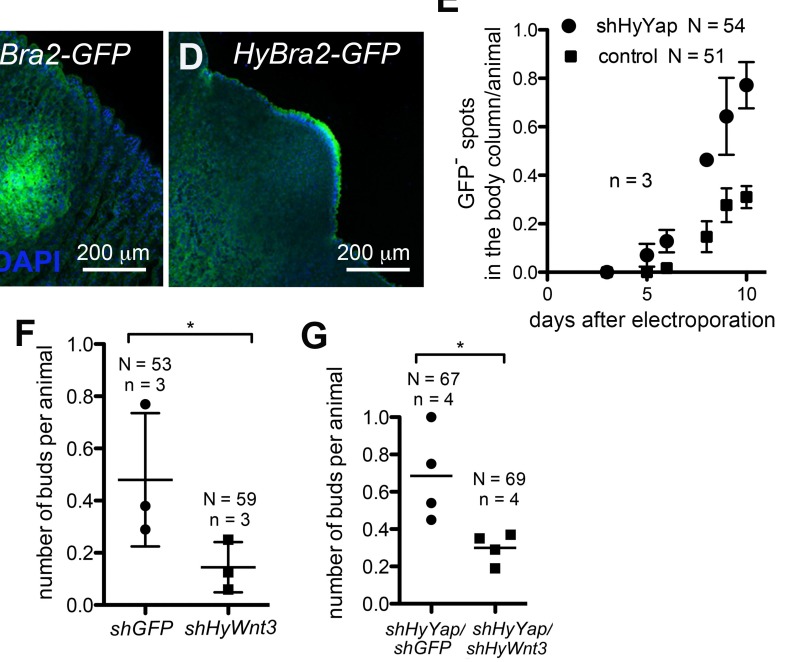

Figure 5 HyYap acts upstream of canonical Wnt signaling during budding.

(A). Whole mount in situ hybridization of Hydra with anti-HyWnt3 probe. Arrows point to areas of $H y W n 3 t$ expression.

(B) Graphs shows the increased number of HyWnt3 spots in the body column of polyps electroporated with shHyYap.

(C,D) Anti-GFP immunostaining of $\mathrm{HyBra2-GFP}$ polyps electroporated with shHyYap, 6 days after electroporation. (C) - apical view, (D) lateral view of $\mathrm{GFP}^{+}$bud.

(E) Graph shows the increased number of $\mathrm{GFP}^{+}$spot in the body column of HyBra2-GFP polyps electroporated with shHyYap.

(F) Graph shows decreased budding rate in polyps electroporated with shHyWnt compared to hydras electroporated with shGFP. $\mathrm{N}$ - number of animals, $\mathrm{n}$ - number of experiments.

(G) Graph shows the decreased budding rate in polyps electroporated with shHyYap/shHyWnt compared with hydras electroporated with shHyYap alone. 
We also examined expression of $\mathrm{HyBra2}$, a hypostome-specific gene, which is induced by Wnt expression [39]. HyBra2 is expressed early in budding and expression persists in the hypostome of the growing bud [39]. We used a transgenic Hydra line that expresses GFP under the control of the HyBra2 promoter [40] to assay induction of budding upon loss of HyYap (Figures 5C and D). GFP patches were observed in the budding zone in a significantly higher number of animals upon electroporation with shHyYap compared to controls (Figure 5E), indicating that HyBra2 expression is activated upon loss of HyYap.

Knockdown of shHyWnt3 alone results in reduced production of buds, as expected from the key role of HyWnt3 in axis initiation [41](Figure 5F). To test if budding by loss of HyYap is mediated by increased HyWnt3, we simultaneously knocked down HyYap and HyWnt3. Importantly, the increased budding that resulted from downregulation of HyYap was suppressed when shHyWnt3 was electroporated along with shHyYap (Figure 5G). These data indicate that HyYAP negatively regulates HyWnt3 expression to suppress bud formation in Hydra. The Hippo pathway thus integrates growth and axis formation by controlling Wnt signaling.

\section{Discussion}

The canonical Wnt (Wnt/ $\beta$-catenin) pathway is both necessary and sufficient for axis formation in cnidarians: transplantation of the hypostome, the organizer, into a body column of a host, or experimental induction of canonical Wnt signaling leads to formation of a new axis [4, 5, 7]. However, in Hydra, the onset of HyWnt3 expression occurs after the first signs of bud formation [14] pointing to events regulating budding upstream of HyWnt3. Early studies connected budding to the cell cycle and cell displacement in Hydra [10, 11, 42], however, molecular mechanisms connecting these processes were never illuminated.

In a normally fed Hydra polyp, the rate of cell division is similar along the body column [11]. Due to continuous cell division, cells below the subtentacle zone are being pushed down the body column [11]. In the budding zone, excess cells are forced out of the maternal axis to form a new axis, a bud [10]. Buds do not form in starved Hydra, since the rate of cell division can not compensate for the rate of cell loss at the ends [13]. Ectodermal epithelial cells that are about to form a bud are packed tighter than cells of the body column: they elongate in apico-basal direction and reduce the area of attachment to mesoglea, the basement membrane (Fig. 1F) [20]. Nuclear localization of mammalian and Drosophila Yap is negatively regulated 
by cell density $[22,29]$. Similar, we find that in Hydra, highly packed cells of the budding zone have less nuclear HyYap than body column cells, and, especially than the flat cells of the peduncle and tentacles (Figures 2 and 6A). Since downregulation of HyYap leads to induction of budding, we suggest that HyYap might act as a molecular link between continuous cell division and budding (Figure 6B). A seeming paradox is that loss of HyYap reduces proliferation. However, knocking down of HyYap does not completely block epithelial cell division. In addition, when HyYap is knocked down locally, the rest of the body column cells continue to divide, pushing electroporated cells into the budding zone and aboral end.
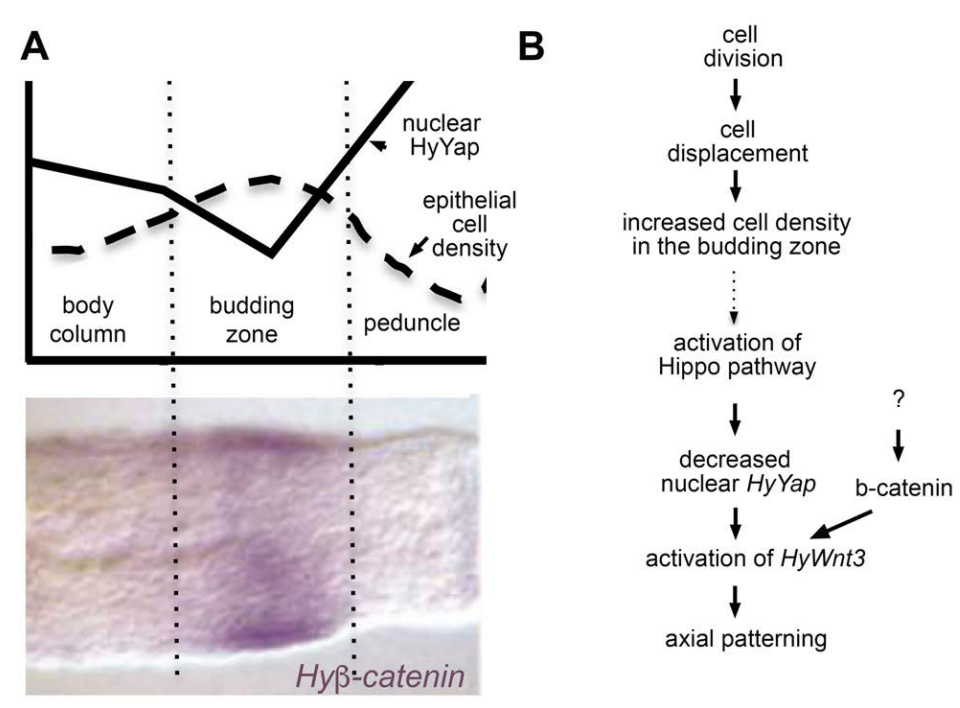
Figure 6 The proposed role of the Hippo pathway in axis formation in Hydra.
(A) Schematic drawings of the axial distributions of epithelial cell density (adapted from [11]) and nuclear HyYap superimposed over Hy $\beta$-catenin in situ (adapted from [14]).
(B) Hypothetical model identifying HyYap as a molecular link between cell division and axis formation in Hydra. Dotted arrow indicates causal connection based on analogy with Drosophila and mammals that yet has to be demonstrated in Hydra.

We show that the Hippo pathway regulates budding by attenuating canonical Wnt signaling. Yap and its homologues Yorkie and TAZ also bind and inhibit Wnt signaling by binding Disheveled $[43,44]$. Yap and TAZ also bind and inhibit $\beta$ catenin [45]. Interestingly, buds that were induced by knocking down of HyYap always formed at the normal location, the budding zone, in spite of the larger knockdown area. Intriguingly, expression of $H y \beta$-catenin is also higher in the budding zone than in surrounding body column tissue (Figure 6A) [14]. Hy $\beta$ catenin can directly activate transcription of HyWnt3 [15]. Thus, induction of $H y W n t 3$ through release of Hy $\beta$-catenin upon knocking down of HyYap is a possible scenario. Also required for budding is noncanonical Wnt signaling. Noncanonical Wnt activation occurs in the densely packed ectodermal cells early in budding, before the onset of HyWnt3 expression, and depends on Hy $\beta$-catenin [16]. Whether noncanonical Wnt signaling operates downstream of Hippo or in a parallel pathway is an intriguing subject for future research. 
Inhibition of the Hippo pathway by knocking down HyLATS results in dramatic shortening and thickening of tentacles. IF and EM analyses show that HyLATS knockdown leads to major changes in the actin cytoskeleton and epithelial cell shape. Interestingly, inhibition of Wart (LATS) in Drosophila stimulates polymerization of F-actin in a Yorkie-independent manner, by acting on the capping protein $[46,47]$. In contrast, in mammalian cells, activation of F-actin requires the transcription activity of Yap [48]. In Hydra, knocking down of HyYap rescues the shLATS phenotype, suggesting a role for HyYap transcriptional control of actin. Abnormal polymerization of actin could explain the randomized orientation of the muscle processes and misfolding of mesoglea seen in the HyLATS knockdown.

To summarize, we show that the conserved LATS-Yap-Hippo signaling pathway plays a major role in morphogenesis in the cnidarian Hydra, and acts upstream of canonical Wnt signaling and expression of Wnt3 during axis initiation. Our findings demonstrate that the amount of nuclear Yap decreases in the budding zone due to Hippo activation induced by high cell density in this zone, and that reduction of nuclear Yap leads to activation of Wnt/ $\beta$-catenin signaling and budding (Figure 6B). We speculate that Hippo signaling, and nuclear Yap serve to link continuous cell division, cell density, and axis formation early in metazoan evolution (Figure 6B).

\section{Acknowledgements}

We thank Joe Culotti (LTRI, Toronto) for invaluable support of the project and help in writing the manuscript, Leonid Brown (University of Guelph) for help with culturing Hydra, Marina Gertsenstein (Toronto Center for Phenogenomics) for help with the electroporation procedure, Thomas Bosch (University of Kiel) for providing GFP transgenic Hydra, Taylor Skokan (Universoty of California, San Francisco) for providing the MRLC-GFP transgenic Hydra, Celina Juliano (University of California, Davis) for providing anti-HyWi antibody.

\section{References}

1. Meinhardt, H. (2008). Models of biological pattern formation: from elementary steps to the organization of embryonic axes. Curr Top Dev Biol 81, 1-63. 
2. Niehrs, C. (2010). On growth and form: a Cartesian coordinate system of Wnt and BMP signaling specifies bilaterian body axes. Development 137, 845-857.

3. Petersen, C.P., and Reddien, P.W. (2009). Wnt signaling and the polarity of the primary body axis. Cell 139, 1056-1068.

4. Broun, M., Gee, L., Reinhardt, B., and Bode, H.R. (2005). Formation of the head organizer in hydra involves the canonical Wnt pathway. Development 132, 2907-2916.

5. Browne, E.N. (1909). The production of new hydrants in hydra by the insertion of small grafts. Journal of Experimental Zoology 7, 1 - 37.

6. Gee, L., Hartig, J., Law, L., Wittlieb, J., Khalturin, K., Bosch, T.C., and Bode, H.R. (2010). betacatenin plays a central role in setting up the head organizer in hydra. Dev Biol 340, 116124.

7. Trevino, M., Stefanik, D.J., Rodriguez, R., Harmon, S., and Burton, P.M. (2011). Induction of canonical Wnt signaling by alsterpaullone is sufficient for oral tissue fate during regeneration and embryogenesis in Nematostella vectensis. Dev Dyn 240, 2673-2679.

8. Trembley, A. (1744). Mémoires pour servir à l'histoire d'un genre de polypes d'eau douce, à bras en forme de cornes, (Leide,: J. \& H. Verbeek).

9. Bode, H.R. (1996). The interstitial cell lineage of hydra: a stem cell system that arose early in evolution. J Cell Sci 109 ( Pt 6), 1155-1164.

10. Campbell, R.D. (1967). Tissue dynamics of steady state growth in Hydra littoralis. II. Patterns of tissue movement. J Morphol 121, 19-28.

11. Campbell, R.D. (1967). Tissue dynamics of steady state growth in Hydra littoralis. I. Patterns of cell division. Dev Biol 15, 487-502.

12. Bode, H.R. (2009). Axial patterning in hydra. Cold Spring Harb Perspect Biol 1, a000463.

13. Otto, J.J., and Campbell, R.D. (1977). Tissue economics of hydra: regulation of cell cycle, animal size and development by controlled feeding rates. J Cell Sci 28, 117-132.

14. Hobmayer, B., Rentzsch, F., Kuhn, K., Happel, C.M., von Laue, C.C., Snyder, P., Rothbacher, U., and Holstein, T.W. (2000). WNT signalling molecules act in axis formation in the diploblastic metazoan Hydra. Nature 407, 186-189.

15. Nakamura, Y., Tsiairis, C.D., Ozbek, S., and Holstein, T.W. (2011). Autoregulatory and repressive inputs localize Hydra Wnt3 to the head organizer. Proc Natl Acad Sci U S A 108, 9137-9142.

16. Philipp, I., Aufschnaiter, R., Ozbek, S., Pontasch, S., Jenewein, M., Watanabe, H., Rentzsch, F., Holstein, T.W., and Hobmayer, B. (2009). Wnt/beta-catenin and noncanonical Wnt signaling interact in tissue evagination in the simple eumetazoan Hydra. Proc Natl Acad Sci U S A 106, 4290-4295.

17. Aufschnaiter, R., Wedlich-Soldner, R., Zhang, X., and Hobmayer, B. (2017). Apical and basal epitheliomuscular F-actin dynamics during Hydra bud evagination. Biol Open 6, 11371148.

18. Meng, Z., Moroishi, T., and Guan, K.L. (2016). Mechanisms of Hippo pathway regulation. Genes Dev 30, 1-17.

19. Otto, J.J., and Campbell, R.D. (1977). Budding in Hydra attenuata: bud stages and fate map. J Exp Zool 200, 417-428.

20. Graf, L., and Gierer, A. (1980). Size, shape and orientation of cells in budding hydra and regulation of regeneration in cell aggregates. Wilehm Roux Arch Dev Biol 188, 141-151. 
21. Huang, J., Wu, S., Barrera, J., Matthews, K., and Pan, D. (2005). The Hippo signaling pathway coordinately regulates cell proliferation and apoptosis by inactivating Yorkie, the Drosophila Homolog of YAP. Cell 122, 421-434.

22. Zhao, B., Wei, X., Li, W., Udan, R.S., Yang, Q., Kim, J., Xie, J., Ikenoue, T., Yu, J., Li, L., et al. (2007). Inactivation of YAP oncoprotein by the Hippo pathway is involved in cell contact inhibition and tissue growth control. Genes Dev 21, 2747-2761.

23. Reginensi, A., Enderle, L., Gregorieff, A., Johnson, R.L., Wrana, J.L., and McNeill, H. (2016). A critical role for NF2 and the Hippo pathway in branching morphogenesis. Nat Commun 7, 12309.

24. Sebe-Pedros, A., Zheng, Y., Ruiz-Trillo, I., and Pan, D. (2012). Premetazoan origin of the hippo signaling pathway. Cell Rep 1,13-20.

25. Coste, A., Jager, M., Chambon, J.P., and Manuel, M. (2016). Comparative study of Hippo pathway genes in cellular conveyor belts of a ctenophore and a cnidarian. EvoDevo 7, 4.

26. Hilman, D., and Gat, U. (2011). The evolutionary history of YAP and the hippo/YAP pathway. Mol Biol Evol 28, 2403-2417.

27. Unni, M., Reddy, P.C., Pal, M., Sagi, I., and Galande, S. (2021). Identification of Components of the Hippo Pathway in Hydra and Potential Role of YAP in Cell Division and Differentiation. Front Genet 12, 676182.

28. Basu, S., Totty, N.F., Irwin, M.S., Sudol, M., and Downward, J. (2003). Akt phosphorylates the Yes-associated protein, YAP, to induce interaction with 14-3-3 and attenuation of p73mediated apoptosis. Mol Cell 11,11-23.

29. Oh, H., and Irvine, K.D. (2008). In vivo regulation of Yorkie phosphorylation and localization. Development 135, 1081-1088.

30. Vogg, M.C., Beccari, L., Iglesias Olle, L., Rampon, C., Vriz, S., Perruchoud, C., Wenger, Y., and Galliot, B. (2019). An evolutionarily-conserved Wnt3/beta-catenin/Sp5 feedback loop restricts head organizer activity in Hydra. Nat Commun 10, 312.

31. Watanabe, H., Schmidt, H.A., Kuhn, A., Hoger, S.K., Kocagoz, Y., Laumann-Lipp, N., Ozbek, S., and Holstein, T.W. (2014). Nodal signalling determines biradial asymmetry in Hydra. Nature 515, 112-115.

32. Karabulut, A., He, S., Chen, C.Y., McKinney, S.A., and Gibson, M.C. (2019). Electroporation of short hairpin RNAs for rapid and efficient gene knockdown in the starlet sea anemone, Nematostella vectensis. Dev Biol 448, 7-15.

33. Wittlieb, J., Khalturin, K., Lohmann, J.U., Anton-Erxleben, F., and Bosch, T.C. (2006). Transgenic Hydra allow in vivo tracking of individual stem cells during morphogenesis. Proc Natl Acad Sci U S A 103, 6208-6211.

34. Overholtzer, M., Zhang, J., Smolen, G.A., Muir, B., Li, W., Sgroi, D.C., Deng, C.X., Brugge, J.S., and Haber, D.A. (2006). Transforming properties of YAP, a candidate oncogene on the chromosome 11q22 amplicon. Proc Natl Acad Sci U S A 103, 12405-12410.

35. Siebert, S., Farrell, J.A., Cazet, J.F., Abeykoon, Y., Primack, A.S., Schnitzler, C.E., and Juliano, C.E. (2019). Stem cell differentiation trajectories in Hydra resolved at single-cell resolution. Science 365.

36. Bode, H.R., Flick, K.M., and Smith, G.S. (1976). Regulation of interstitial cell differentiation in Hydra attenuata. I. Homeostatic control of interstitial cell population size. J Cell Sci 20, 29-46.

37. Hao, Y., Chun, A., Cheung, K., Rashidi, B., and Yang, X. (2008). Tumor suppressor LATS1 is a negative regulator of oncogene YAP. J Biol Chem 283, 5496-5509. 
38. Teefy, B.B., Siebert, S., Cazet, J.F., Lin, H., and Juliano, C.E. (2020). PIWI-piRNA pathwaymediated transposable element repression in Hydra somatic stem cells. RNA 26, 550-563.

39. Bielen, H., Oberleitner, S., Marcellini, S., Gee, L., Lemaire, P., Bode, H.R., Rupp, R., and Technau, U. (2007). Divergent functions of two ancient Hydra Brachyury paralogues suggest specific roles for their C-terminal domains in tissue fate induction. Development 134, 4187-4197.

40. Glauber, K.M., Dana, C.E., Park, S.S., Colby, D.A., Noro, Y., Fujisawa, T., Chamberlin, A.R., and Steele, R.E. (2013). A small molecule screen identifies a novel compound that induces a homeotic transformation in Hydra. Development 140, 4788-4796.

41. Lengfeld, T., Watanabe, H., Simakov, O., Lindgens, D., Gee, L., Law, L., Schmidt, H.A., Ozbek, S., Bode, H., and Holstein, T.W. (2009). Multiple Wnts are involved in Hydra organizer formation and regeneration. Dev Biol 330, 186-199.

42. Webster, G., and Hamilton, S. (1972). Budding in hydra: the role of cell multiplication and cell movement in bud initiation. J Embryol Exp Morphol 27, 301-316.

43. Barry, E.R., Morikawa, T., Butler, B.L., Shrestha, K., de la Rosa, R., Yan, K.S., Fuchs, C.S., Magness, S.T., Smits, R., Ogino, S., et al. (2013). Restriction of intestinal stem cell expansion and the regenerative response by YAP. Nature 493, 106-110.

44. Varelas, X., Miller, B.W., Sopko, R., Song, S., Gregorieff, A., Fellouse, F.A., Sakuma, R., Pawson, T., Hunziker, W., McNeill, H., et al. (2010). The Hippo pathway regulates Wnt/beta-catenin signaling. Dev Cell 18, 579-591.

45. Imajo, M., Miyatake, K., Iimura, A., Miyamoto, A., and Nishida, E. (2012). A molecular mechanism that links Hippo signalling to the inhibition of Wnt/beta-catenin signalling. EMBO J 31, 1109-1122.

46. Fernandez, B.G., Gaspar, P., Bras-Pereira, C., Jezowska, B., Rebelo, S.R., and Janody, F. (2011). Actin-Capping Protein and the Hippo pathway regulate F-actin and tissue growth in Drosophila. Development 138, 2337-2346.

47. Lucas, E.P., Khanal, I., Gaspar, P., Fletcher, G.C., Polesello, C., Tapon, N., and Thompson, B.J. (2013). The Hippo pathway polarizes the actin cytoskeleton during collective migration of Drosophila border cells. J Cell Biol 201, 875-885.

48. Calvo, F., Ege, N., Grande-Garcia, A., Hooper, S., Jenkins, R.P., Chaudhry, S.I., Harrington, K., Williamson, P., Moeendarbary, E., Charras, G., et al. (2013). Mechanotransduction and YAPdependent matrix remodelling is required for the generation and maintenance of cancerassociated fibroblasts. Nat Cell Biol 15, 637-646. 


\section{Supplemental Information}

\begin{tabular}{|c|c|}
\hline $\begin{array}{l}\text { DNA oligo template for } \\
\text { shRNA synthesis }\end{array}$ & \\
\hline GFP sense & $\begin{array}{l}\text { TAATACGACTCACTATAGAAGATGGAAACATTCTTGGATTCAAGAGATCCAA } \\
\text { GAATGTTTCCATCTTCTT }\end{array}$ \\
\hline GFP a-sense & $\begin{array}{l}\text { AAGAAGATGGAAACATTCTTGGATCTCTTGAATCCAAGAATGTTTCCATCTT } \\
\text { CTATAGTGAGTCGTATTA }\end{array}$ \\
\hline HyYap1 sense & $\begin{array}{l}\text { TAATACGACTCACTATAGACCTCCTCCGTCTCTAGATTCAAGAGAATCTAGA } \\
\text { GACGGAGGAGGTCTT }\end{array}$ \\
\hline HyYap1 a-sense & $\begin{array}{l}\text { AAGACCTCCTCCGTCTCTAGATTCTCTTGAATCTAGAGACGGAGGAGGTCTA } \\
\text { TAGTGAGTCGTATTA }\end{array}$ \\
\hline HyYap2 sense & $\begin{array}{l}\text { TAATACGACTCACTATACGACAAGACTCAGACACTGTTCAAGAGACAGTGTC } \\
\text { TGAGTCTTGTCGTT }\end{array}$ \\
\hline HyYap2 a-sense & $\begin{array}{l}\text { AACGACAAGACTCAGACACTGTCTCTTGACAGTGTCTGAGTCTTGTCGTATA } \\
\text { GTGAGTCGTATTA }\end{array}$ \\
\hline HyYap1 scrambled sense & $\begin{array}{l}\text { TAATACGACTCACTATAGAGCCCCTTAACGCTTCTCTTCAAGAGAAGAGAAG } \\
\text { CGTTAAGGGGCTCTT }\end{array}$ \\
\hline HyYap1 scrambled a-sense & $\begin{array}{l}\text { AAGAGCCCCTTAACGCTTCTCTTCTCTTGAAGAGAAGCGTTAAGGGGCTCTA } \\
\text { TAGTGAGTCGTATTA }\end{array}$ \\
\hline HyYap2 scrambled sense & $\begin{array}{l}\text { TAATACGACTCACTATAGGTCAACCGCTCATAACAATCAAGAGATTGTTATG } \\
\text { AGCGGTTGACCTT }\end{array}$ \\
\hline HyYap2 scrambled a-sense & $\begin{array}{l}\text { AAGCGAAACCGCAACATGACTTCTCTTGAAGTCATGTTGCGGTTTCGCTATA } \\
\text { GTGAGTCGTATTA }\end{array}$ \\
\hline HyLATS1 sense & $\begin{array}{l}\text { TAATACGACTCACTATAGGTGTCAAGCGTTCTTACTTTCAAGAGAAGTAAGA } \\
\text { ACGCTTGACACCTT }\end{array}$ \\
\hline HyLATS a-sense & $\begin{array}{l}\text { AAGGTGTCAAGCGTTCTTACTTCTCTTGAAAGTAAGAACGCTTGACACCTAT } \\
\text { AGTGAGTCGTATTA }\end{array}$ \\
\hline HyLATS2 sense & $\begin{array}{l}\text { TAATACGACTCACTATAGACCAAGAGCAAATGAGAATTCAAGAGATTCTCAT } \\
\text { TTGCTCTTGGTCTT }\end{array}$ \\
\hline HyLATS2 a-sense & $\begin{array}{l}\text { AAGACCAAGAGCAAATGAGAATCTCTTGAATTCTCATTTGCTCTTGGTCTAT } \\
\text { AGTGAGTCGTATTA }\end{array}$ \\
\hline HyWnt3 - 1 sense & $\begin{array}{l}\text { TAATACGACTCACTATAGCAACGTAAGTGGAACTGTTCAAGAGAACAGTTCC } \\
\text { ACTTACGTTGCTT }\end{array}$ \\
\hline HyWnt3 - 1 a-sense & $\begin{array}{l}\text { AAGCAACGTAAGTGGAACTGTTCTCTTGAACAGTTCCACTTACGTTGCTATA } \\
\text { GTGAGTCGTATTA }\end{array}$ \\
\hline
\end{tabular}


bioRxiv preprint doi: https://doi.org/10.1101/2022.01.19.476962; this version posted January 20, 2022. The copyright holder for this preprint (which was not certified by peer review) is the author/funder. All rights reserved. No reuse allowed without permission.

\begin{tabular}{|l|l|}
\hline HyWnt3 - 2 sense & $\begin{array}{l}\text { TAATACGACTCACTATAGTTGACGGTTGCGAACTTATCAAGAGATAAGTTCG } \\
\text { CAACCGTCAACTT }\end{array}$ \\
\hline HyWnt3 - 2 a-sense & $\begin{array}{l}\text { AAGTTGACGGTTGCGAACTTATCTCTTGATAAGTTCGCAACCGTCAACTATA } \\
\text { GTGAGTCGTATTA }\end{array}$ \\
\hline $\begin{array}{l}\text { DNA oligos for qPCR } \\
\text { analysis }\end{array}$ & ATTTGCCAGAAGGTTGGGAACGTG \\
\hline HyYap F & TGTTGACGATGACGCTTCTCTTGC \\
\hline HyYap R & \\
\hline HyLATS F & GGTCCTGGAGCCTATGCGTT \\
\hline HyLATS R & GCAGAACGCTTTGCAGGTGA \\
\hline
\end{tabular}

Table S1 DNA oligonucleotides used in the study. T7 promoter sequence is in red, gap sequence is in blue. 
bioRxiv preprint doi: https://doi.org/10.1101/2022.01.19.476962; this version posted January 20, 2022. The copyright holder for this preprint (which was not certified by peer review) is the author/funder. All rights reserved. No reuse allowed without permission.

A $:$ identity 100.00 HyYap 35.48 DmYorki 34.04 MmYap1 33.68 HsYap2

HyYap DmYorki MmYap1 HsYap2 HyYap DmYorki MmYap1 HsYap2

HyYap DmYorki MmYap1 HsYap2

HyYap DmYorki MmYap1 HsYap2

HyYap DmYorki MmYap1 HsYap2

HyYap DmYorki MmYapl HsYap2

HyYap DmYorki MmYapl HsYap2
1 [ MCACLIAKIILCSFRLYTISAFYMLTTMSASSNT-------------------NSLIEKEIDDEDMISPIKSNNI

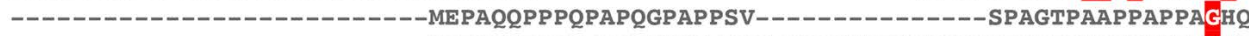

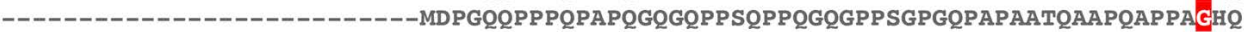

81

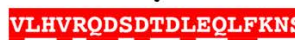

KDIPRSKPFRDRKLPASFFRPPPSL FTDOTA VVRVNODTDDNLOALFDSVNPGDAKRPLOLPLRMRKLPNSFFTPPAPSHSRANSADSTYDAGSOSS INIGNKAS IVQOP VVHVRGDSETDLEALFNAVMNPKTANVPOTVPMRLRKLPDSFFKPPEPKSHSROAST---DAGT-

161

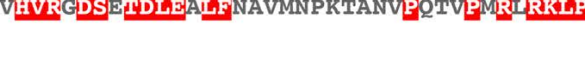

. $\quad$. QLQQQHPQNNF

DGQSPIAA I PQLQIQP S PQHSRLA I HHSRARSSPASLQQNYNVRARSDAAAANNPNANPSSOQOPAGPTFPENSAOEFPS -_- - - -

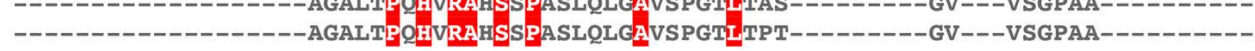

241 $-------$ $:$ 3 SAIDLDAMNTCMSOD I PMSMOTVHKKQRSYDVISPI QLNRQLGALPPGWEQAKTNDGOIYYLNHTTKSTONEDPR

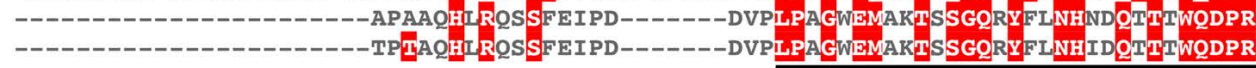

321

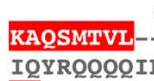

:

WW

TOYROQ⿻ KAMLSQLNVPAP-----_---ASPAVPQTLMNSASGPLPDGWEOAMTODGEVYY INHKNKTTSWLDPRLDPRFAMNORI KAMISQMNVTAP---------TS P PVQQNMMNSASGPLPDGWEQAMTQD GEIYY INHKNKTTSWLDPRLDPRFAMNQRI

401

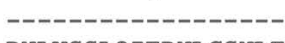
WW

ATIVNPS--SHKPDD-

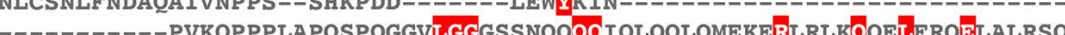
SQSA---------------PVKQP P PLAPQSPQGGVMGGSNSNQQQQMRLQQLQMEKERLRLKQQELIRQELALRSO

481

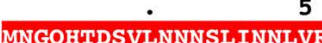
REKLPTLEODGGTPNAVSSPGMSOELRTMTTNSSDPFLNSGTYHSRDESTDSGLSMSSYS IPRIPDDFLNSVDEMDTG-DTI

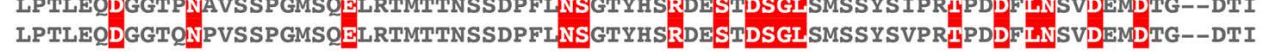

561

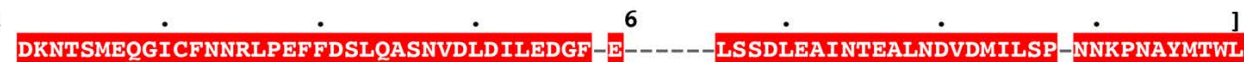
S----QSTLPSQQSRFPDYLEALPGTNVDLGTLEGDAMNIEGEELMPSLOEALSS F్IL-DVESVLAATKLDKESFLTWL N----QSTLPSQQNRF PDYLEAI PGNNVD GTLEGD GMNIEGEELMPSLOEALSSDILNDMESVLAATKLDKESFITKL 
bioRxiv preprint doi: https://doi.org/10.1101/2022.01.19.476962; this version posted January 20, 2022. The copyright holder for this preprint (which was not certified by peer review) is the author/funder. All rights reserved. No reuse allowed without permission.

$\begin{array}{cl}\text { identity } & \\ 100.00 & \text { HyLats } \\ 43.88 & \text { DrLats1 } \\ 41.30 & \text { DrLats2 } \\ 43.34 & \text { DmLats }\end{array}$

HyLats

DrLats 1

DrLats2

DmLats

HyLats

DrLats 1

DrLats2

DmLats

HyLats

DrLats 1

DrLats2

DmLats

HyLats

DrLats 1

DrLats2

DmLats

HyLats

DrLats 1

DrLats2

DmLats

HyLats

DrLats 1

DrLats 2

DmLats

HyLats

DrLats 1

DrLats2

DmLats

HyLats

DrLats 1

DrLats2

DmLats

HyLats

DrLats 1

DrLats 2

DmLats

HyLats

DrLats 1

DrLats2

DmLats

HyLats

DrLats 1

DrLats2

DmLats

HyLats

DrLats 1

DrLats2

DmLats

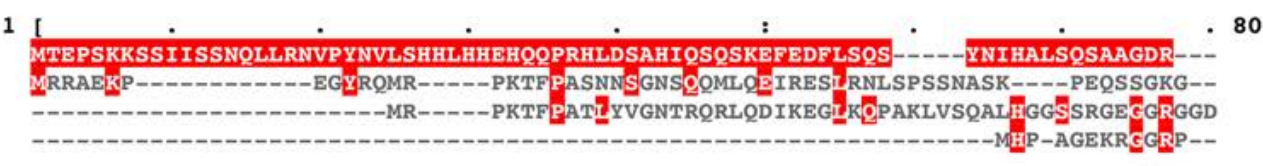

81

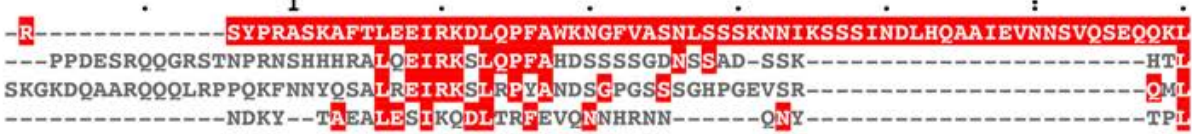

61 SOLVSYGXDEAIAADVLRNNSNKSIEVLVDIL

2 -NSIGCHKMKVPSRVLTNHRVLGNL Q-TQEPGFDEELMVNRINF QEA---------VREQIPSARPVNTAIKOAGPPQIOOPL------LRRQSWKGSK QDLUNAGCDOEMARVALKQTGSRNIEAALEY ISK--MSYLDPHTEQIVRVIKOTSPGKS GMPNLM------DHRTAMEGSG

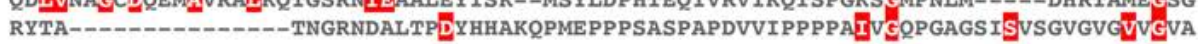

241 $:$
MHFOPSFLOTLONKYA-1 -
ESLAPORHSALIMDVLIYRPSSPGPOSD - - -

3

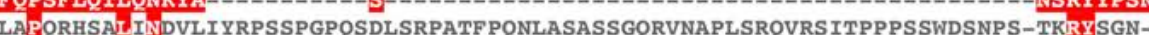
DGALPPYHM---GAPLYEGASYGAEGEM---_-NGRVPKMMMTALMPNKLIRKPSIERDTAS-SHYLRCSPALDSGAGSSRSDSPHSHTH---QPSSRTVGNPGGNGGFSPSP

321

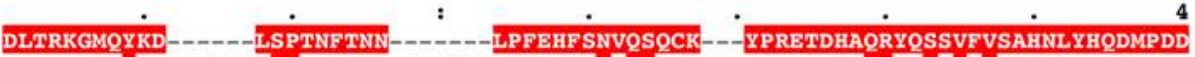
------LDYL----VPRISP-----V-----POGPRGDGY INPOS------------ONORGLSPVPVGROP----I-------PVYMYM----PPPANPSOGSQ-----PSGG BGAHYDYRSH-----------MME--NSSYGUKRSASFONK----

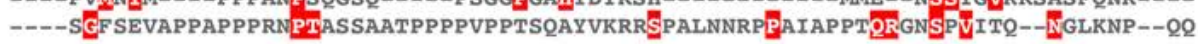

401

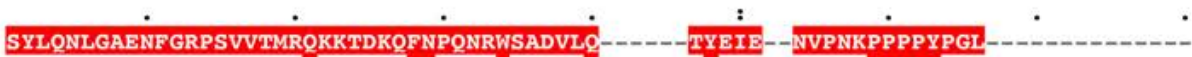
-IMQNSNSNKFNFPPSW----PQNGSMONEYMGMNSGAROPPPPPYSMHOTNROSPTAOOMOS QLTQ

181 KRPSI :

SALTAPPNGASLPQSMLVPNRNSHNLDMYNLGVIRPPVQQAOTPPGQDTSSSW--THSVPGRSNSFTSAPNNR--------AMGGEF SDVPOGLLTPSRASLNLDLYEHHWPGAOGP-EGTPPARQPOGPFRGEVRVPSRTNSENNHOKVTVROTLPP Y-

561
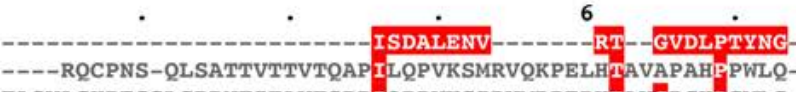

640

AVAPAHFPWLQTASVAGKPESSLGPPNTITAVTSPPIOPPVKSIRVMRPEPKTAVGPCHPGWLSAPLAKP----- QPRVYQARSQQPIIMQSVKSTQVQKPVLOUAVARQSBSSASASNSPVHVLAAPPSYPQKSAAVVQQQQ

641

- YTKNSNHLST-

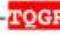

--MIINSPRE

QAAAAAHQQОHОHQQSKPPTPTTPPLVGLNSKP ICLEPPSYAKSMQAKAATVVQQQQQQQQQQQVQQQQVQQQQQQQQQQ

721

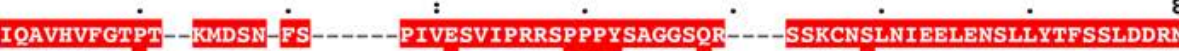

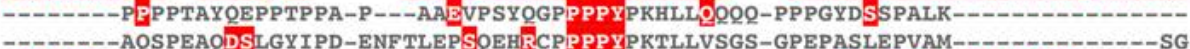
LQALRV్TLAQAQRERDORERERDQOKLANGNPGRQMLPPPPYOSNNNNNSEIKPPSCNNNNIOIS-WSNIATTPPIPPAK

801

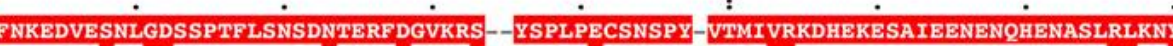

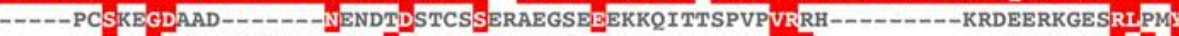
LQ- - DVSATCRTIQSSSVGKOEEP IF FDKVKMGKGEKAVKDKKQIQTSPVPVRKN - - - - - ARDEE-KRESRIKSY Y WN--NSSNIGANSSGGSNGS--.-----TGTTASSSTSCKKIKHASPIPERKK--.----ISKEKEEERKEFRIRQY

881

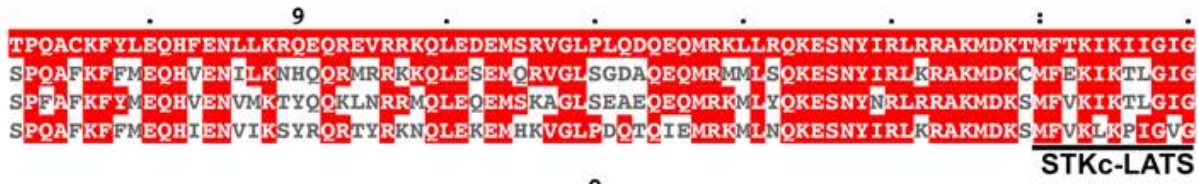

961

0

AFGEVCITRKVDIG-ATS

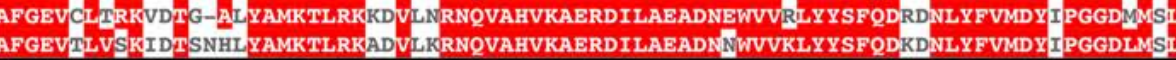


bioRxiv preprint doi: https://doi.org/10.1101/2022.01.19.476962; this version posted January 20, 2022. The copyright holder for this preprint (which was not certified by peer review) is the author/funder. All rights reserved. No reuse allowed without permission.

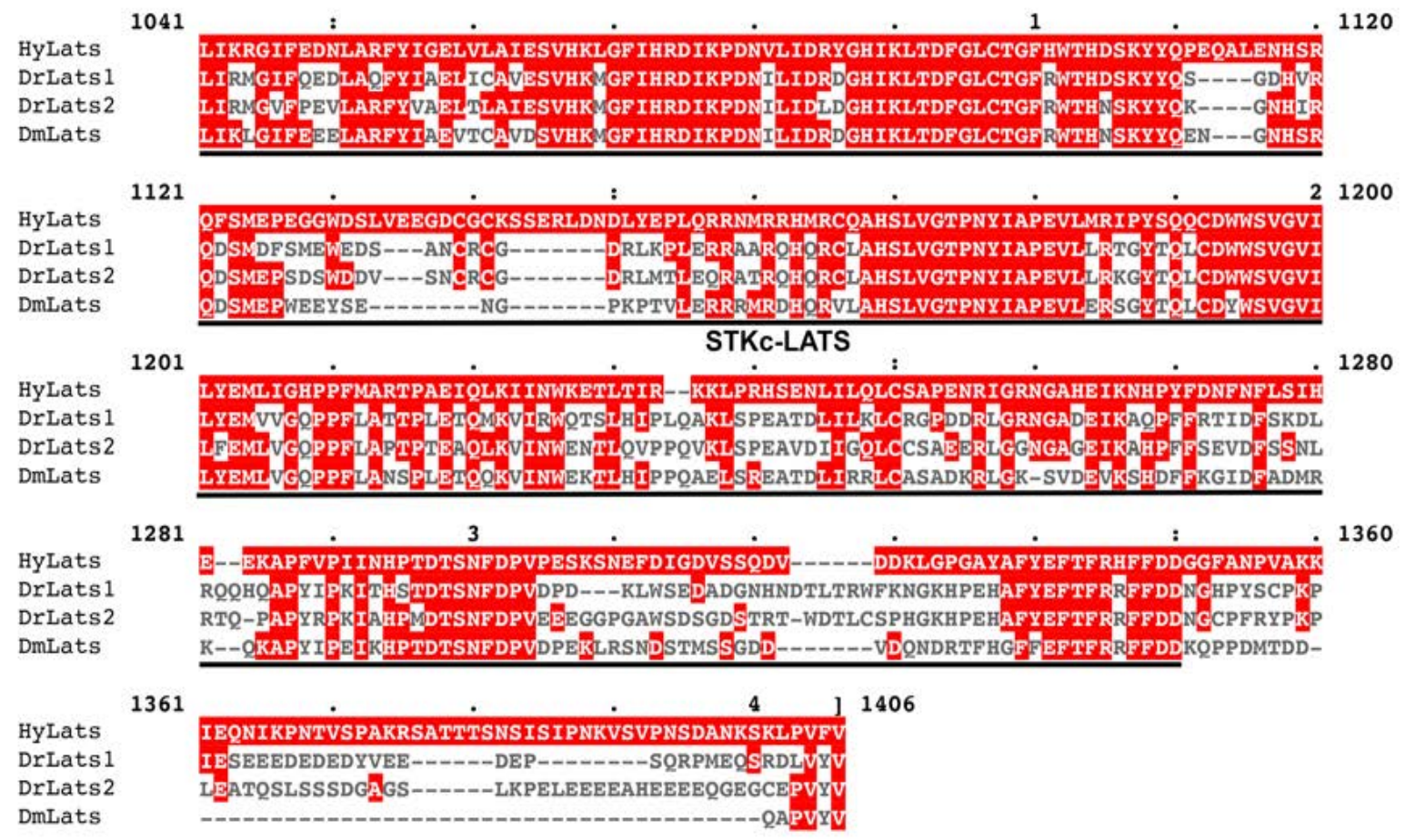


bioRxiv preprint doi: https://doi.org/10.1101/2022.01.19.476962; this version posted January 20, 2022. The copyright holder for this preprint (which was not certified by peer review) is the author/funder. All rights reserved. No reuse allowed without permission.

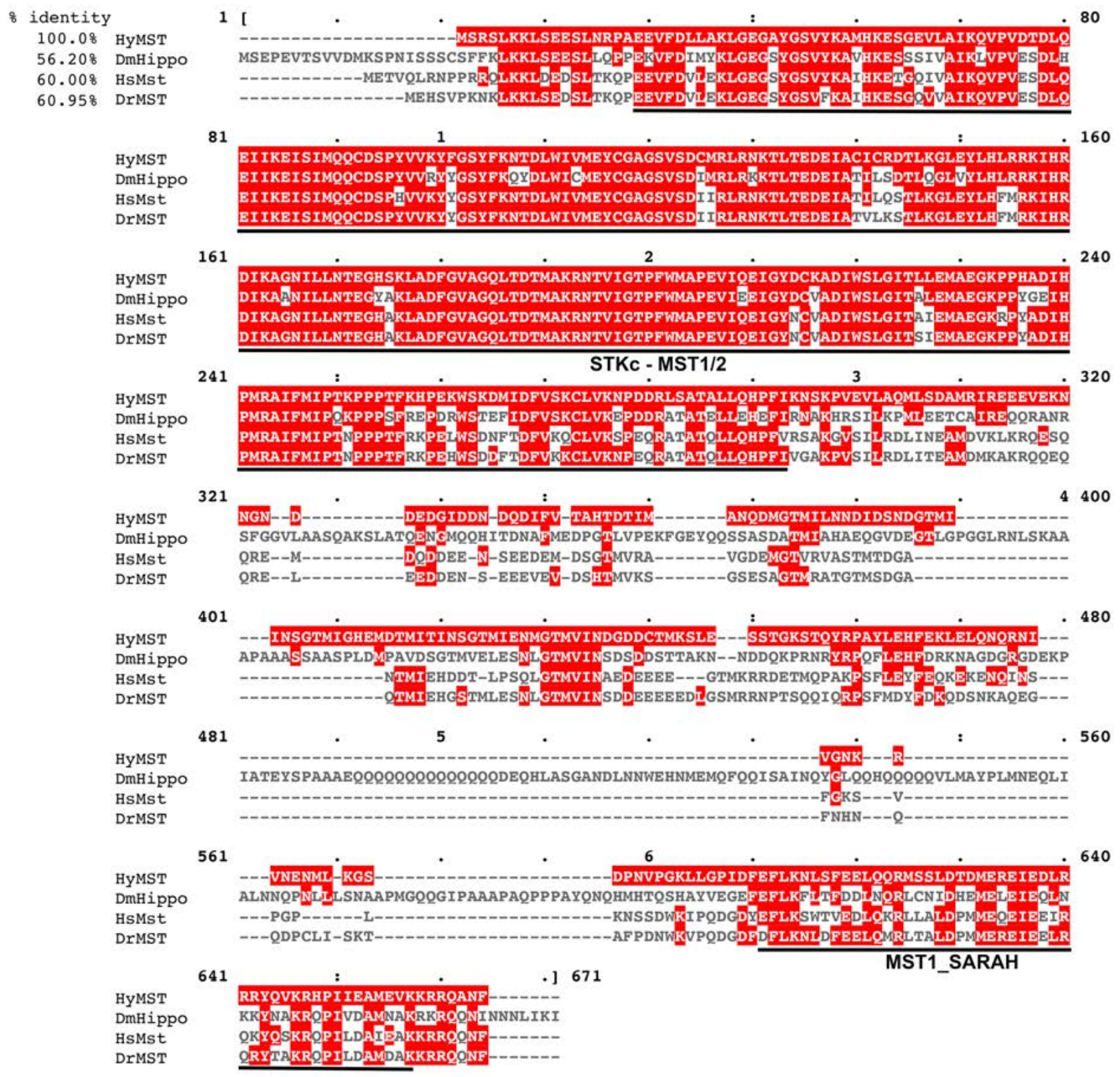


B

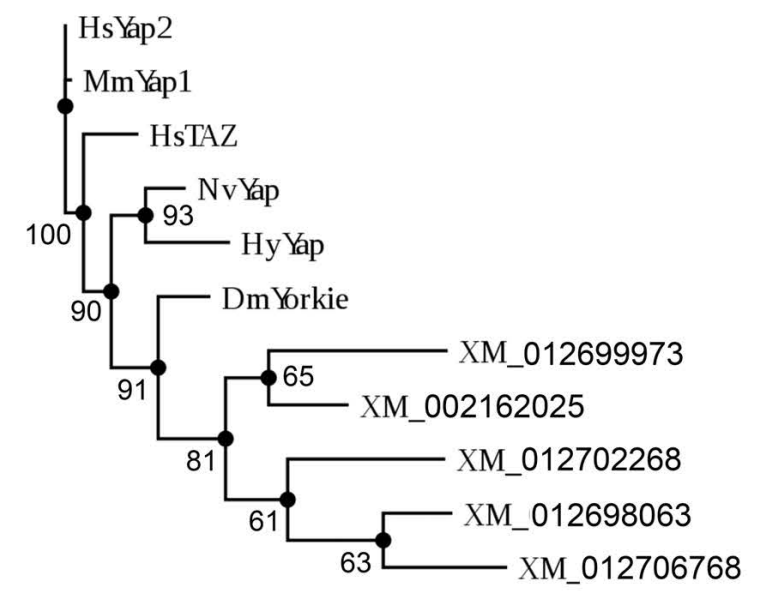

C

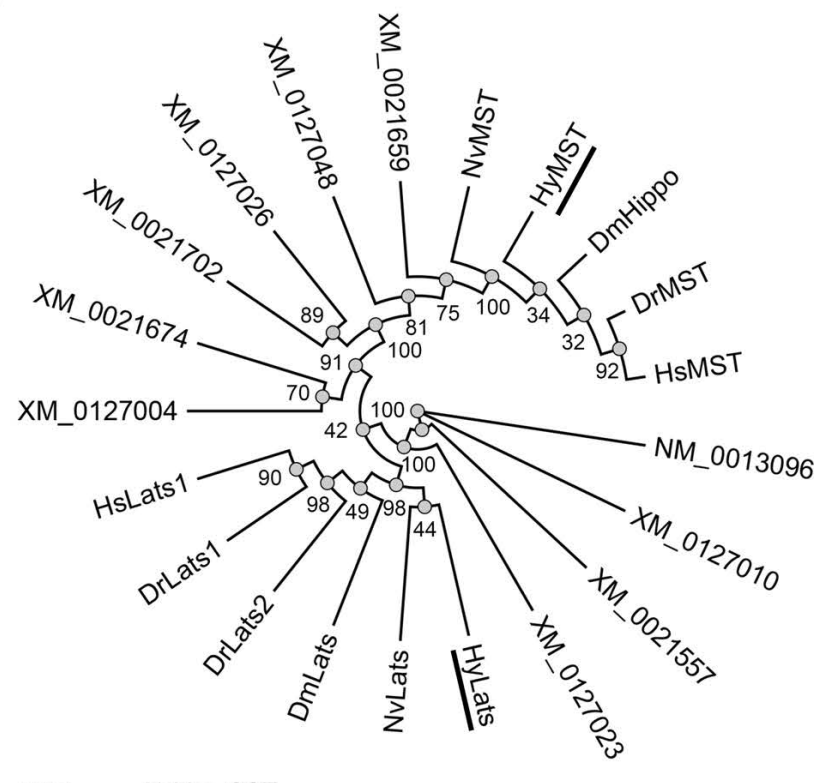

D preabsorbed with GST HyYap-GST
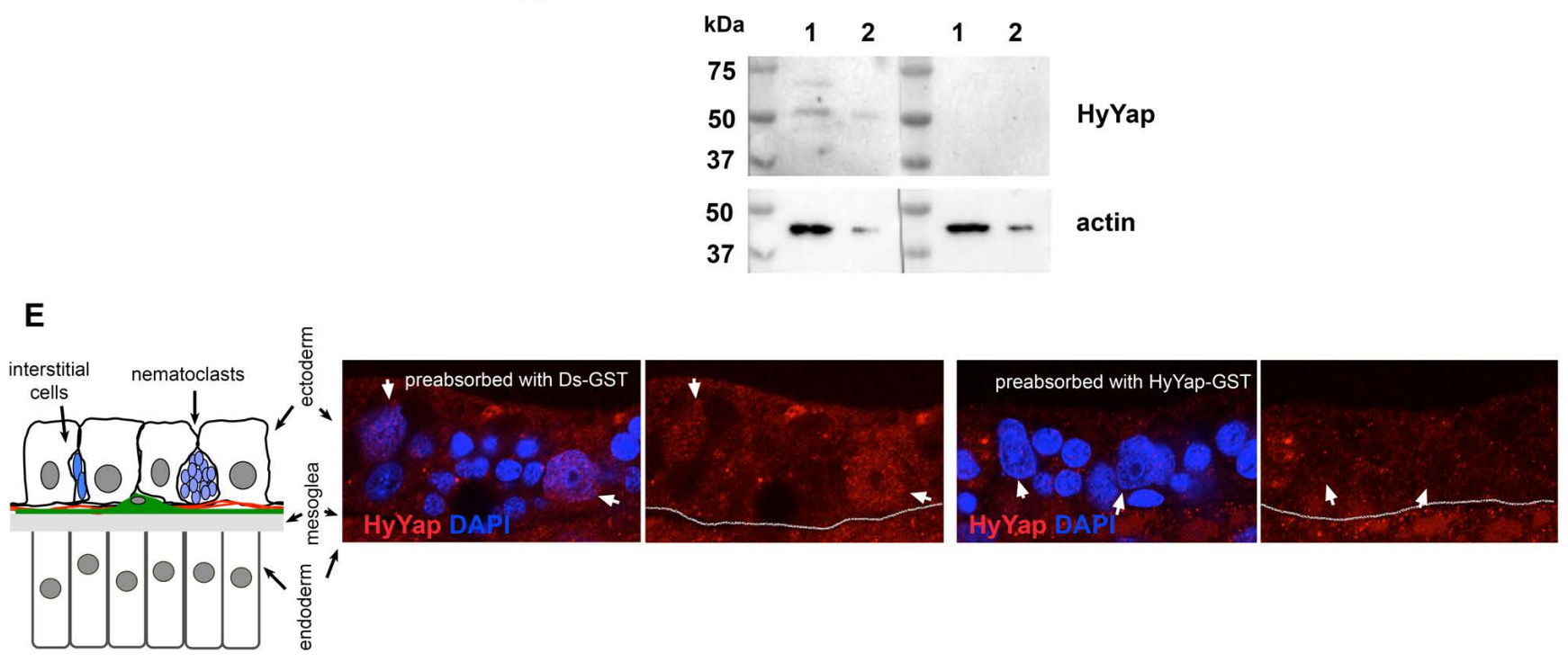

\section{Figure S1}

(A) Alignments of predicted Hydra Yap, LATS and MST proteins with Drosophila and vertebrate homologues. Characteristic domains of proteins are underlined: WW - tryptophan containing domain that binds specific proline-rich sequences, STKc-LATS - catalytic domain of LATS family of serine/threonine kinases, STKc-MST1/2 catalytic domain of MST family of serine/threonine kinases, MST1-SARAH - apoptosis-mediating SARAH domain of MST1 proteins. Dm - Drosophila melanogaster, Mm - Mus musculus, Hs - Homo sapience, Dr - Danio rerio. 
(B) Phylogenetic tree of Yap family proteins based on the complete protein sequence, Maximum Likelihood analysis (100 bootstrap replicates, bootstrap values are indicated for each node); predicted Hydra homologue of Yap is underlined; Hs - Homo sapiens, Mm - Mus musculus, Nv Nematostella vectensis, Hy - Hydra vulgaris, Dm - Drosophila melanogaster; XM_0126999, XM_0021620, XM_0127022, XM_0126980, XM_0127067 sequences that came at the top of BLAST search of Hydra nucleotide databases for Yap; sequences were aligned with Clustal Omega (https://www.ebi.ac.uk/Tools/msa/clustalo/) and analyzed using Akaike Information Criterion (http://www.atgc-montpellier.fr).

(C) Phylogenetic tree of LATS and MST families based on the complete protein sequence, Maximum Likelihood analysis (100 bootstrap replicates, bootstrap values are indicated for each node); predicted Hydra homologues LATS and MST proteins are underlined; XM_012702323, NM_001309671, XM_012701027, XM_002155754, XM_002167407, XM_012700498, XM_002165989, XM_012704879, XM_002170224, XM_012702641, sequences that came at the top of BLAST search of Hydra nucleotide databases for Yap, LATS and MST are included along with predicted homologues; sequences were aligned with Clustal Omega (https://www.ebi.ac.uk/Tools/msa/clustalo/) and analyzed using Akaike Information Criterion (http://www.atgc-montpellier.fr).

(D) Western blot analysis of total Hydra lysates with anti-HyYap serum preabsorbed with either GST or HyYap-GST. Lysates are made from either 3 animals (lanes 1 ) or 1 animal (lanes 2). For the loading control the same blot was immunostained with actin antibodies.

(E) Lateral view of Hydra ectoderm immunostained with anti-HyYap serum preabsorbed with HyDs-GST or with HyYap-GST antigens. Arrows point to the nuclei of ectodermal epithelial cells; schematic drawing of the lateral view of Hydra ecto- and endoderm is shown on the left. 


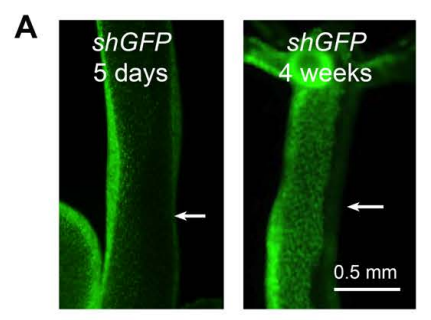

C

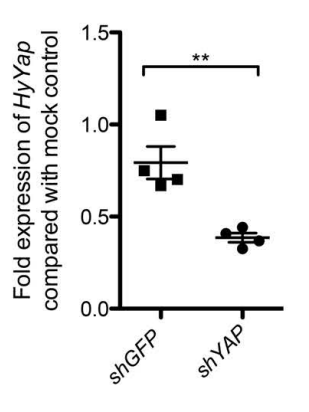

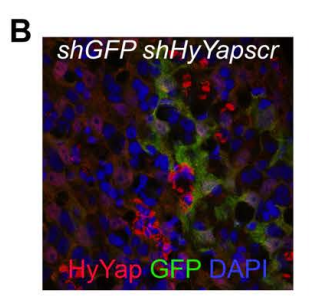

D
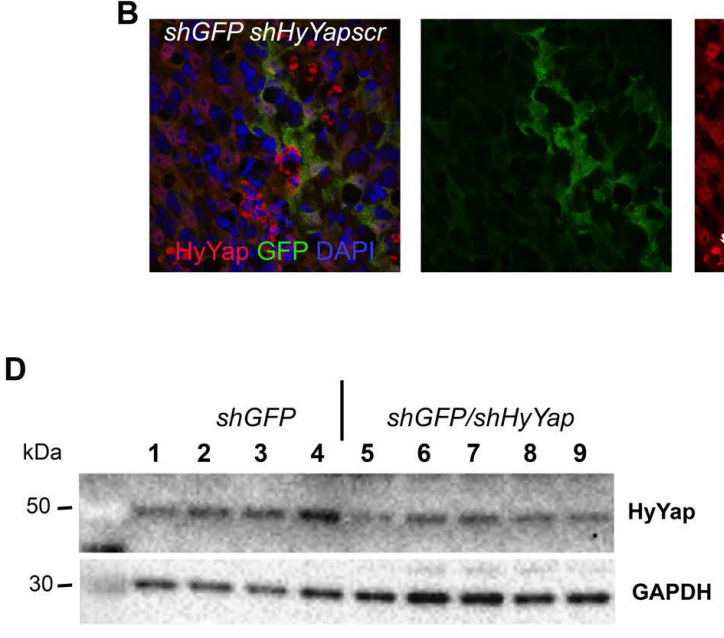

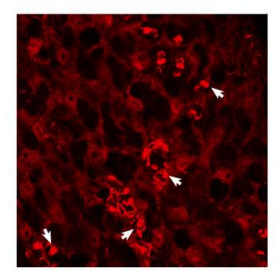

$E$
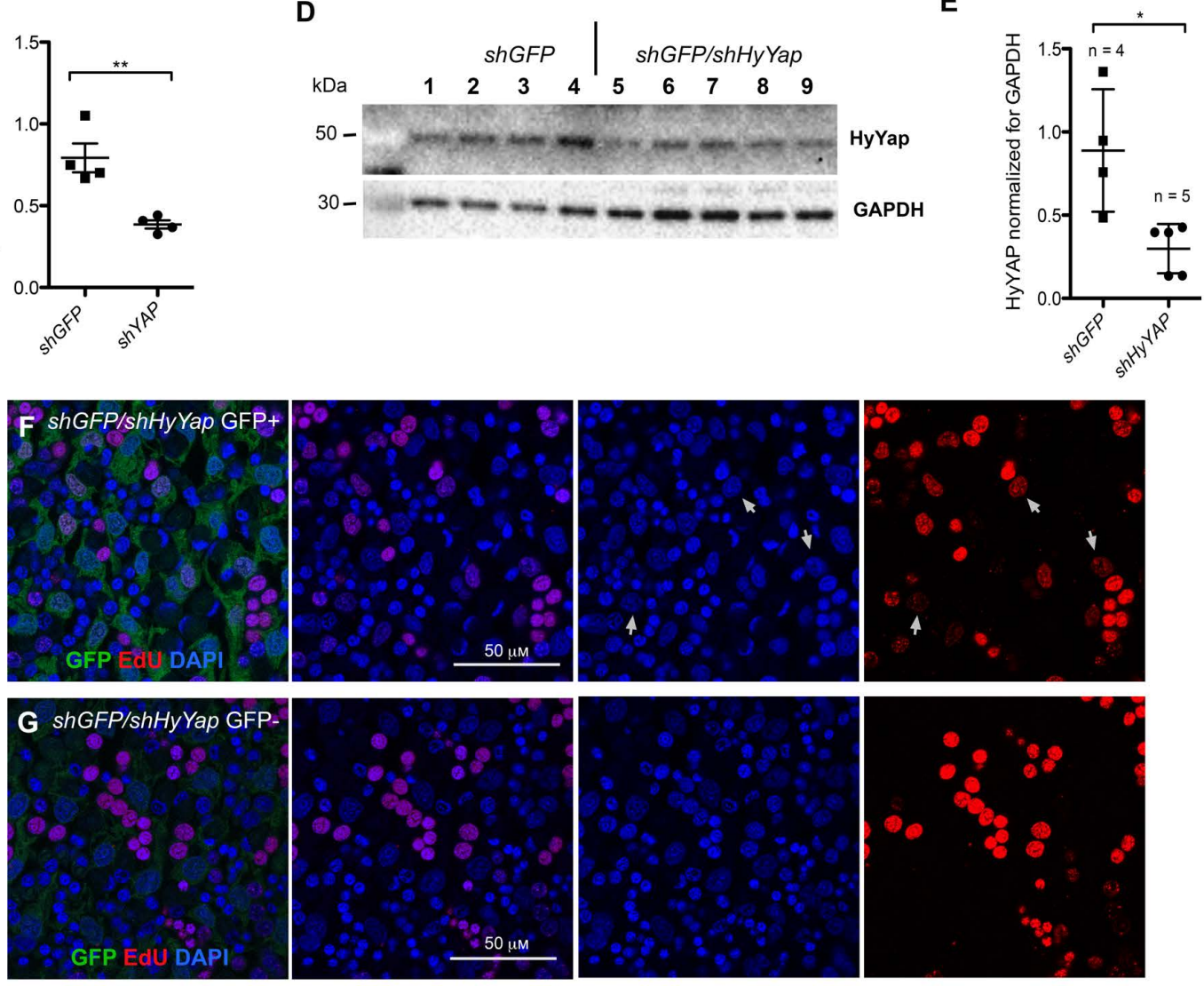

H

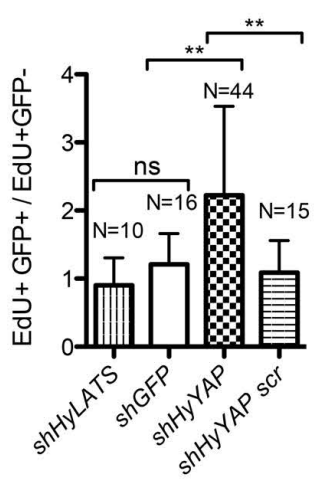

I

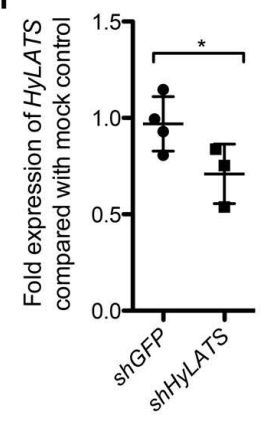

\section{Figure S2}

(A) GFP hydras electroporated with shGFP 5 days and 4 weeks after electroporation. Arrows point to the areas of GFP knockdown. 
(B) Apical view of ectoderm of GFP hydras electroporated with shGFP/shHyYapscr hairpin and immunostained with anti-GFP and antiHyYap antibodies. Arrows point to a non-specific staining of nematocyte capsules that is observed for a variety of antibodies when used Hydra immunostaining protocol

(C) qPCR analysis of HyYap in GFP hydras electroporated with either shGFP or shGFP/shHyYap. 4 animals for each condition.

(D,E) Western blot analysis of total lysate from GFP hydras elecroporated with either shGFP alone or shGFP/shHyYap, 1 animal per lane; $\mathrm{n}$ - number of animals. For the loading control the same blot was immunostained with GAPDH antibodies.

$(F, G)$ Apical view of ectoderm of Hydra ectoderm with shGFP/shHyYap, pulse labeled with EdU 6 days after electroporation and immunostained for GFP and EdU; (F) - GFP+ area, (G) - GFP- area; arrows point to EdU+ epithelial cells.

(H) Graph shows ratio between numbers of EdU+ ectodermal epithelial cells in $\mathrm{GFP}^{+}$and GFP- areas in GFP hydras electroporated with either shGFP alone, shGFP/shHyYap or shGFP/shHyYap scr and pulse-labeled with EdU 6 - 7 days after electroporation; EdU+GFP+/EdU+GFP- ratio was calculated for each individual animal; the total of $60-200$ cell was used in analysis of each animal; $\mathrm{n}$ - number of animals.

(I) qPCR analysis of HyLATS in GFP hydras electroporated with either shGFP or shGFP/shHyLATS. Each point represents an individual animal. 
bioRxiv preprint doi: https://doi.org/10.1101/2022.01.19.476962; this version posted January 20, 2022. The copyright holder for this preprint (which was not certified by peer review) is the author/funder. All rights reserved. No reuse allowed without permission.

A

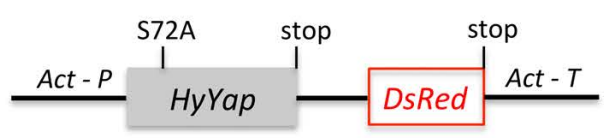

B
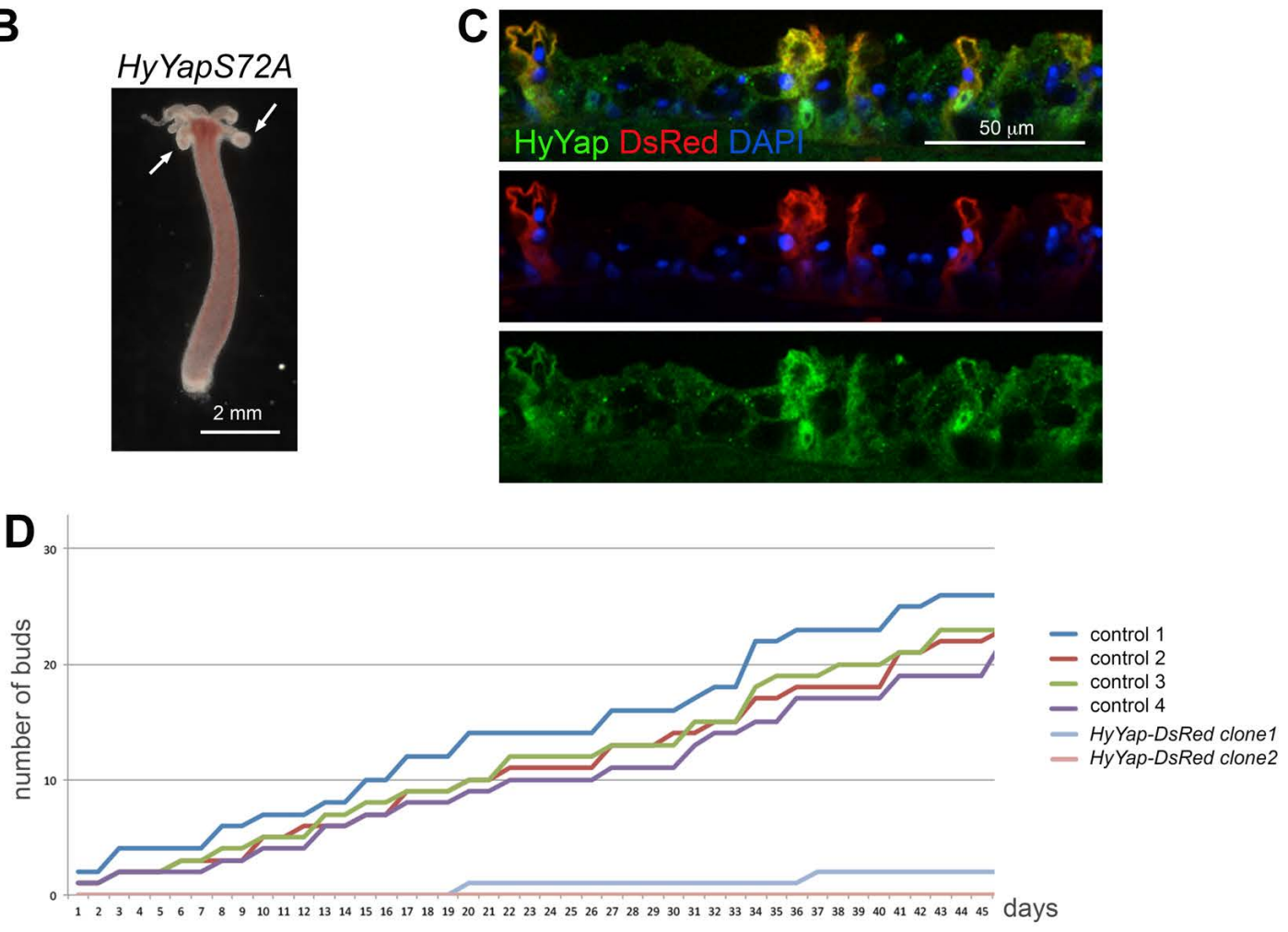

E

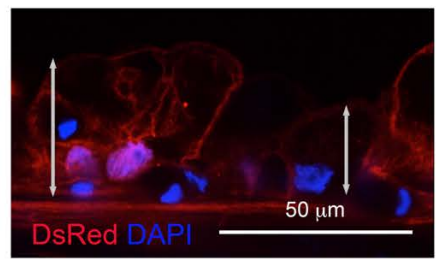

$\mathbf{F}$
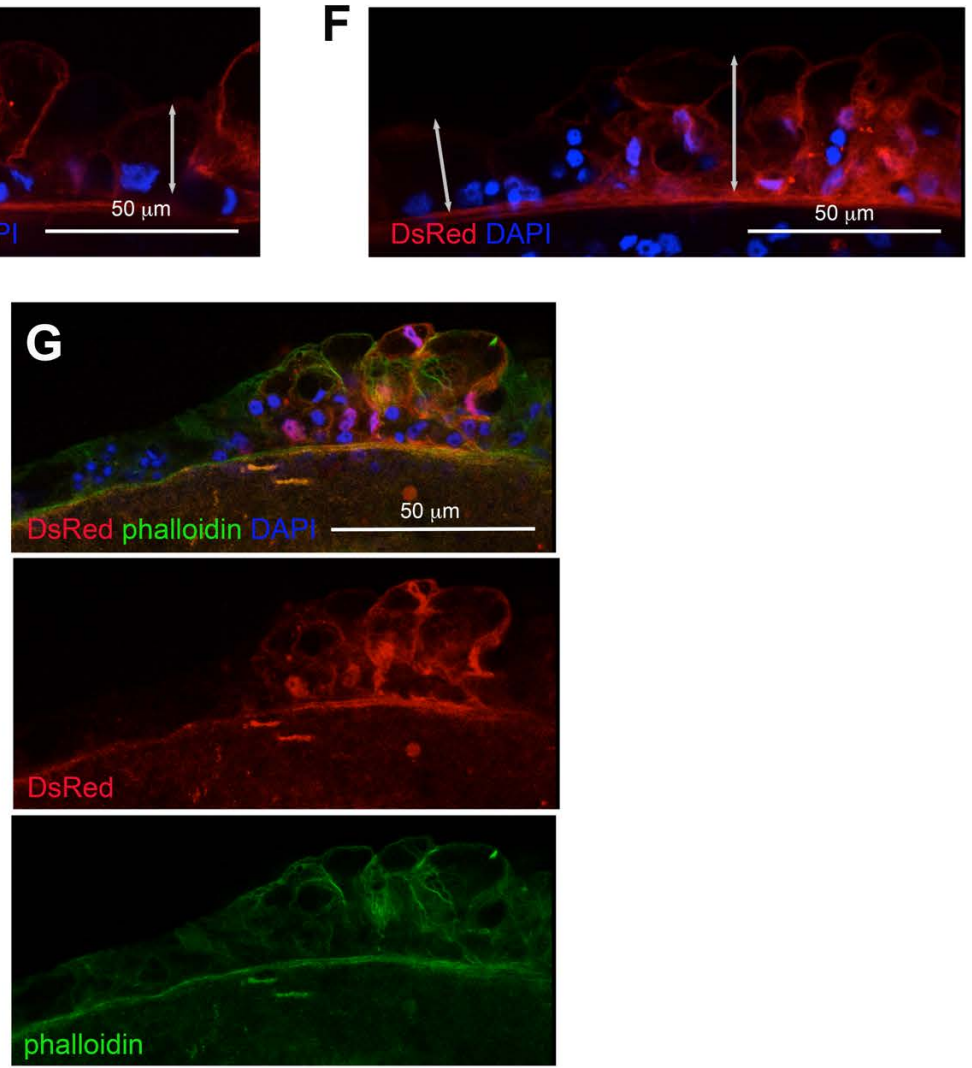


\section{Figure S3}

(A) Schematic drawing of the construct used to generate HyYap-DsRed transgenic Hydra.

(B) Photos of live HyYap-DsRed hydras. Arrows point to the thick tentacles.

(C) Lateral view of the ectoderm of HyYap-DsRed Hydra immunostained for HyYap and DsRed.

(D) Budding rate of control and HyYap-DsRed hydras shown as the number of buds produced by a single polyp over time.

(E) Lateral view of the ectoderm of HyYap-DsRed Hydra immunostained for DsRed. Double-headed arrows indicate the apico-basal dimension of transgenic and wild type cells.

(F) Lateral view of ectoderm of HyYap-DsRed Hydra immunostained for DsRed. Double-headed arrows indicated the apico-basal dimension of transgenic and wild type cells.

(G) Lateral view of the ectoderm of HyYap-DsRed Hydra immunostained for DsRed and phalloidin. 

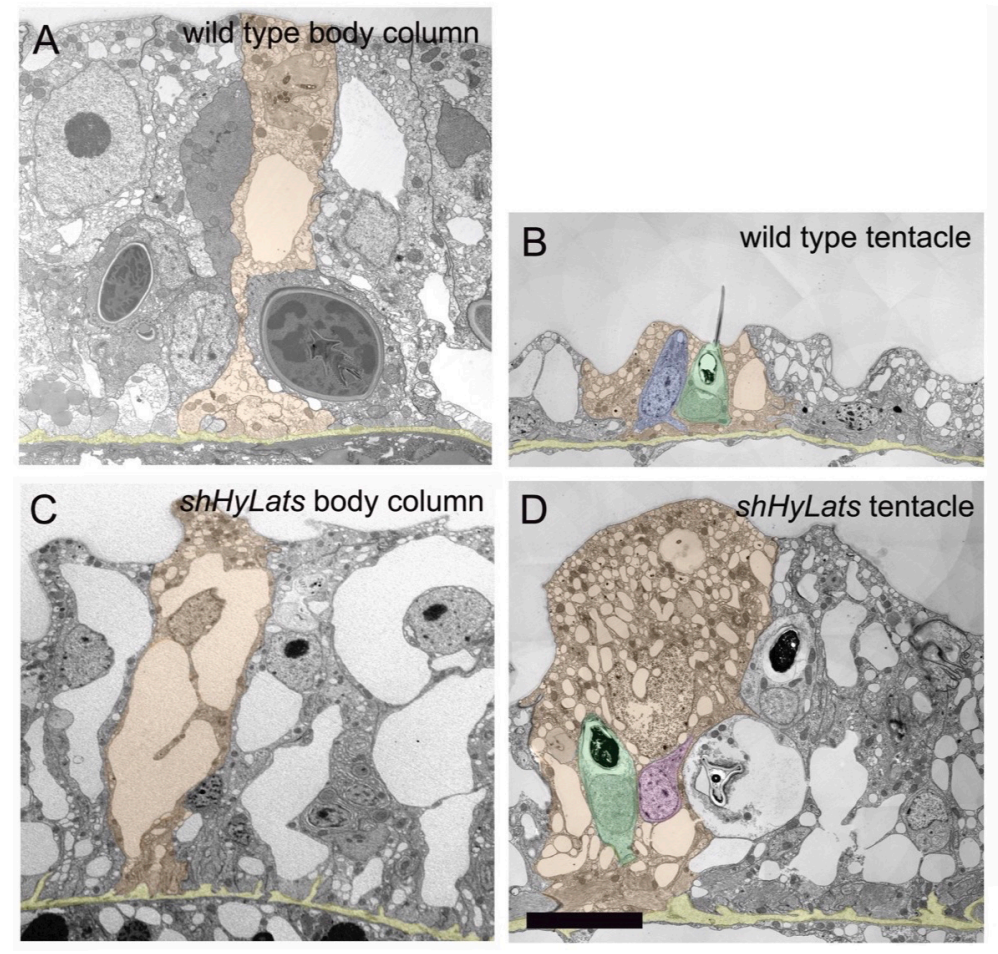

\section{Figure S4 Low magnification transmission electron microscopy images of wild type and shHyLats ectoderm.}

$(A, B)$ Images of body column and tentacle tissue in wild type polyps;

(C,D) Corresponding images of shHyLats polyps. One representative

ectodermal epithelial cell is colored in orange. The mesoglea is colored in yellow. shHyLATS thick tentacles show a dramatic expansion of ectodermal epithelial cells in along their apical-basal axis. They generally exhibit a higher volume of intracellular vacuoles indicating that their osmoregulation is affected. (B) Wild type epithelial cells in the tentacles (called battery cells) incorporate differentiated nematocytes (stinging cells; green) mounted at their apical membrane and a sensory nerve cell (blue). (D) Tentacle epithelial cells in shHyLATS thick tentacles also exhibit incorporated and fully differentiated nematocytes, but these are usually not mounted at the apical membrane. In addition, these cells show interstitial precursor cells (violet), which are not occurring in the tentacles of wild type polyps. Furthermore, shHyLATS polyps exhibit major disruptions of ectodermal basal muscle fibers and mesoglea structure as discussed in detail using high magnification images in the main paper (see Figure 4). Size bar: $20 \mu \mathrm{m}$. 


\section{Material and Methods}

\section{Animal and culture condition}

The AEP strain of $\mathrm{Hydra}$ vulgaris was cultured at $18^{\circ} \mathrm{C}$ in hydra medium $(1.0 \mathrm{mM}$ $\mathrm{CaCl}_{2}, 1 \mathrm{mM} \mathrm{NaHCO}, 0.1 \mathrm{mM} \mathrm{MgCl} 2,0.03 \mathrm{mM} \mathrm{KNO}_{3}, 1 \mathrm{mM}$ TrisHCl pH 7.8, and fed with Artemia nauplii every two days.

\section{In situ hybridization}

All procedures at room temperature were carried out with rotation on a nutator. Animals starved for $48 \mathrm{hr}$ were relaxed in 2\% urethane for 2 min and fixed in $4 \%$ paraformaldehyde $\mathrm{O} / \mathrm{N}$ at $4^{\circ} \mathrm{C}$. Samples were washed for 5 min each in $100 \%$ ethanol $\times 3$, ethanol:PBT 3:1 × 1 , ethanol:PBT 1:1 $\times 1$, ethanol:PBT 1:3 x 1 , $\mathrm{PBT} \times 3$, following by treatment with proteinase $\mathrm{K}(10 \mathrm{mg} / \mathrm{ml})$ and $4 \mathrm{mg} / \mathrm{ml}$ glycine for $10 \mathrm{~min}$ each. Next, smples were treated with $0.1 \mathrm{M}$ triethanolamine $(\mathrm{pH} 7.8) \times 2$ and $0.25 \%(\mathrm{v} / \mathrm{v})$ acetic anhydride in $0.1 \mathrm{M}$ triethanolamine $(\mathrm{pH} 7.8)$ $\times 2$ for 5 min each, washed with PBT for $5 \mathrm{~min} \times 2$ and postfixed with 4\% PFA for $20 \mathrm{~min}$. Fixator was removed by 5 washes with PBT for $5 \mathrm{~min}$. Next, the endogenous alkaline phosphatase was removed by heating samples at $80^{\circ} \mathrm{C}$ for 30 min and washed sequentially in PBT $\times 1$, PBT:Hybridization buffer $(\mathrm{HB}) \times 1$ and $\mathrm{HB} \times 1$ for 10 min each. Samples were pre-hybridized in $\mathrm{HB}$ at $55^{\circ} \mathrm{C}$ for $2 \mathrm{hr}$. Then digoxygenin-labeled RNA probe was added and hybridization was carried out for $48-60 \mathrm{hr}$ at $55^{\circ} \mathrm{C}$. Hybridization solution (HS) was composed of $50 \%$ formamide, $5 \times \mathrm{SSC}$ ( $750 \mathrm{mM} \mathrm{NaCl}, 75 \mathrm{mM}$ sodium citrate), $0.02 \%$ (w/v) each Ficoll, bovine serum albumin (BSA, Fraction V), and polyvinylpyrolidone, 200 $\mathrm{mg} / \mathrm{ml}$ yeast tRNA, $100 \mathrm{mg} / \mathrm{ml}$ heparin, $0.1 \%$ Tween 20 , and $0.1 \%$ Chaps. To remove unhybridized probe samples were washed at $55^{\circ} \mathrm{C}$ for $10 \mathrm{~min}$ each in HS, HS: $2 \times$ SSC $3: 1$, HS: $2 \times$ SSC $1: 1$, HS: $2 \times$ SSC $1: 3$, following by two 30 min washes with $0.1 \%$ CHAPS in $2 \times$ SSC. In a preparation for binding with the antidioxygenin antibody samples were moved at room temperature and washed twice for $10 \mathrm{~min}$ in MAB (100 mM maleic acid, $150 \mathrm{mMNaCl}, \mathrm{pH}$ 7.5), then for 30 min in 1\% BSA in MAB, and then blocked for $2 \mathrm{hr}$ in blocking solution (BS) (80\% MAB-BSA, 20\% heat-inactivated sheep serumn). Alkaline phosphataseconjugated anti-digoxy genin Fab fragments were diluted 1:400 in BS and preabsorbed for at least $2 \mathrm{hr}$ against fixed hydra. The preabsorbed Fab fragments were diluted to a final dilution of 1:2000 in BS and incubated with samples overnight at $4^{\circ} \mathrm{C}$. Next day the unbound antibodies were removed by 8 washes with $\mathrm{MAB}$ for 30 min each, samples were equilibrated with the alkaline phosphatase staining buffer NTMT (100 mMNaCl, 100 mMTris, pH 9.5, 50 
$\mathrm{mMMgCl}_{2}, 0.1 \%$ Tween-20) in three 5 min washes, with the final wash also containing $1 \mathrm{mM}$ Levamisole. Alkaline phosphatase reaction was carried out at $37^{\circ} \mathrm{C}$ in NTMT in the presence of $5 \mathrm{ml} / \mathrm{ml} \mathrm{NBT}$ and $3.75 \mathrm{ml} / \mathrm{ml}$ BCIP in the dark. Reaction was stopped with EtOH, refixed in 3.7\% formaldehyde, dehydrated in ethanol series $2 \mathrm{~min}$ each $(70 \% \mathrm{EtOH} \times 1,95 \% \mathrm{EtOH} \times 1,100 \% \mathrm{EtOH} \times 2)$ and mounted in Euparal.

128 - 663 bp segment of Hydra Wnt3 coding sequence (accession number AF272673) was used to make an in situ probe. Digoxygenin-labeled RNA probes were made according to the protocol supplied by Roche.

\section{Database search and Phylogenetic Analysis}

To identify cnidarian homologues of Fat-like, Ds and CELSR proteins we searched the NCBI (http://www.ncbi.nlm.nih.gov) and NHGRI (https://research.nhgri.nih.gov) databases. We have identified Hydra vulgaris homologues of Yap (NM_001309649), Hippo (MST) (XM_004212124) and LATS (XM_012698864). Sequences used in the analysis and their accession numbers: DmYorkie (DQ099897), MmYap1 (BC094313), HsYap2 (AAP92710), HsTAZ (AJ299431), NvYap (XM_001627445.2), DrLATS1 (XM_005160312), DrLATS2 (NM_001128256), DmLATS (Warts) (U29608), HsLATS1 (AF104413), NvLATS (XM_001628046), HsMST (U18297), DmMST (Hippo), NvMST (XM_032384310), DrMST (BC164215). For generation of the phylogenetic tree, the sequences were aligned using MAFFT (https://www.ebi.ac.uk/Tools/msa/mafft/) or Clutal Omega (https://www.ebi.ac.uk/Tools/msa/clustalo/) and analyzed using Alaike Information Criterion (http://www.atgc-montpellier.fr).

\section{Production of antibodies}

A peptide corresponding to residues 1 - 159 of HyYap was expressed as GSTfusions using the GEX4t-1 vector (Millipore) in E. coli strain BL21 and purified on glutathione-agarose (Thermo Scientific). Purified protein was used to immunize guinea pigs (Cocalico Biologicals).

\section{Immunoblot and Immunofluorescence analysis}

For immunoblotting, polyps were dissolved in lysis buffer (5\% SDS; $10 \%$ glycerol; $60 \mathrm{mM}$ Tris-HCl, pH 6.8) containing 2\% beta-mercaptoethanol, boiled for $5 \mathrm{~min}$, chilled on ice for $5 \mathrm{~min}$ and electrophoresed in a 10\% SDS-PAGE polyacrylamide gel. Transfer of the proteins onto a PVDF membrane was done in transfer buffer (20\% methanol, $25 \mathrm{mM}$ Tris base, $192 \mathrm{mM}$ glycine) overnight 
at $4^{\circ} \mathrm{C}$. The membranes were incubated with antibodies (total anti-HyYap serum was used at 1:1000 dilution, anti-actin (clone C4, Millipore) at 1:2000 dilution, anti-GAPDH (Sigma) at 1:1000 dilution) in blocking buffer (TBS-tween 0.1\% containing 5\% powdered milk) for 90 minutes at RT. After $3 \times 10$ min washes with TBS-T, membranes were incubated with HRP-conjugated secondary antibody (GE Healthcare) diluted 1:10000 in blocking buffer for $1 \mathrm{~h}$ at RT. Visualization was done by ECL detection (Thermo Scientific).

To perform immunocytochemistry on whole mounts animals were relaxed in $2 \%$ urethane for 2 minutes, and then fixed in either Lavdovski's fixative (ethanol:formaldehyde:acetic acid: $\mathrm{H}_{2} \mathrm{O}$ 50:10:4:36) for HyYap and GFP antibodies, or in $4 \%$ paraformaldehyde for phalloidin staining overnight at $4{ }^{\circ} \mathrm{C}$. Then, animals were washed $3 \times 10$ min in PBT (PBS with $0.1 \%$ Triton), animals fixed with $4 \%$ paraformaldehyde were permeabilized in PBS with $1.0 \%$ Triton for $30 \mathrm{~min}$, and incubated in PBT with 2\% BSA for 1 hour. Samples were incubated with primary antibodies overnight at $4^{\circ} \mathrm{C}$. Then, animals were washed $3 \times 10$ min PBT, incubated with secondary antibodies for $30 \mathrm{~min}$, washed with PBT $3 \times 10$ min and mounted using Vectashield mounting medium containing DAPI (Vector Laboratories, Inc). Primary antibodies dilutions were as follows: anti-HyYap total serum, 1:1000; anti-GFP (Abcam, ab13970). Fluor-conjugated secondary antibodies (Jackson Laboratory) were used at 1:400 dilution. Alexa555-phalloidin (Abcam) was used at 1:2000 dilution.

\section{Measurement of immunofluorescent intensity}

To measure the intensity of immunofluorescence $1.5 \mathrm{~mm}$ z-stack confocal images were analyzed by NIS-Elements AR Analysis.

\section{shRNA production and electroporation}

shRNAs were designed and made according to [1]. For each gene two hairpins were synthesized (See Table S1) and both were used for electroporation at 1:1 ratio. Electroporation procedure was performed according to [2].

1. Karabulut, A., He, S., Chen, C.Y., McKinney, S.A., and Gibson, M.C. (2019). Electroporation of short hairpin RNAs for rapid and efficient gene knockdown in the starlet sea anemone, Nematostella vectensis. Dev Biol 448, 7-15.

2. Vogg, M.C., Beccari, L., Iglesias Olle, L., Rampon, C., Vriz, S., Perruchoud, C., Wenger, Y., and Galliot, B. (2019). An evolutionarily-conserved 
bioRxiv preprint doi: https://doi.org/10.1101/2022.01.19.476962; this version posted January 20, 2022. The copyright holder for this preprint (which was not certified by peer review) is the author/funder. All rights reserved. No reuse allowed without permission.

Wnt3/beta-catenin/Sp5 feedback loop restricts head organizer activity in Hydra. Nat Commun 10, 312. 